\title{
Chile: Subsidios, crédito y déficit habitacional
}

\author{
Fernando Garcia de Freitas, Ana Lélia Magnabosco \\ y Patricia H. F. Cunba
}

RESUMEN

El presente artículo tiene los siguientes objetivos: analizar los efectos del subsidio habitacional en el acceso al crédito y la inversión inmobiliaria y estudiar la influencia de esas relaciones en la experiencia chilena. Luego de examinar los sistemas de financiamiento y subsidios en Chile, se propone un modelo teórico que permita analizar los efectos de los subsidios en el crédito habitacional y el equilibrio del mercado inmobiliario. Ese modelo aporta nuevos puntos de vista sobre el papel de la política de subsidios y la estructura en que se funda la investigación empírica. El análisis econométrico corrobora las dos principales propuestas teóricas, a saber: el acceso al subsidio aumenta la probabilidad de que una familia obtenga crédito y reduce el número de familias en situación de déficit habitacional. Los resultados econométricos también ayudan a interpretar la evolución del déficit en Chile.

PALABRAS CLAVE

CLASIFICACIÓN JEL
Vivienda, necesidades de vivienda, subsidios de vivienda, crédito, modelos econométricos, datos estadísticos, financiación de la vivienda, Chile

R21, R28, H53

Fernando Garcia de Freitas, Cámara Brasileña de Servicios (cNs), Brasil. fernando.garcia.freitas@gmail.com Ana Lélia Magnabosco, Universidad de São Paulo, Brasil. analeliamag@yahoo.com.br Patrícia H. F. Cunha, Pontificia Universidad Católica de São Paulo, Brasil. paticunha@uol.com.br 


\section{I}

\section{Introducción}

A mediados de los años setenta se promovió en Chile una profunda reforma del sistema de financiamiento inmobiliario con el objetivo explícito de ampliar las inversiones en viviendas y combatir el déficit en ese ámbito. Se crearon mecanismos innovadores que combinaron créditos y subsidios y tuvieron un efecto inmediato en el mercado.

Además de constituir una experiencia satisfactoria de financiamiento inmobiliario y servir como referencia a otros países de América Latina, el caso chileno ofrece una buena base empírica para analizar cómo una política de subsidios puede influir en las decisiones de los agentes y en el volumen de las inversiones inmobiliarias. Entre otras cosas, esto se debe a que - al tratarse de una política aplicada desde hace muchos años- ya es posible observar sus efectos a largo plazo. Por otra parte, la gran diversidad de modalidades de adquisición de viviendas permite evaluar mejor las relaciones entre subsidio, crédito e ingresos. La financiación de las viviendas puede realizarse mediante subsidios, crédito, autofinanciación sin subsidios y, por último, mediante una combinación de crédito y subsidios.
El artículo se divide en cinco secciones además de esta Introducción. Mientras que en la segunda sección se describe el modelo chileno de financiamiento y se exponen los principales programas de subsidios, en la tercera sección se propone un modelo teórico para analizar cómo influyen los subsidios en el crédito habitacional y el equilibrio del mercado inmobiliario. Ese modelo entrega nuevos puntos de vista respecto del papel de la política de subsidios y proporciona la estructura en que se basa la investigación empírica realizada en las secciones siguientes. En la cuarta sección se realiza un análisis econométrico para investigar la influencia de los subsidios en la probabilidad de obtención de crédito inmobiliario, que además de ayudar en la interpretación de la experiencia chilena, brinda elementos empíricos que corroboran el modelo teórico propuesto. En la quinta sección se presenta la metodología de estimación del déficit en Chile y se detallan los cálculos realizados a partir de los datos de la Encuesta de Caracterización Socioeconómica Nacional (CASEN). También se incluye otra investigación econométrica inspirada en las relaciones entre las variables que determinan la inversión inmobiliaria. El artículo se cierra con una sección de consideraciones finales.

\section{II}

\section{Resumen de la política de vivienda en Chile}

La política de vivienda chilena se caracteriza por tres dimensiones: i) el sistema de financiamiento; ii) la política de subsidios, y iii) la normativa en materia de construcción y urbanización. Cada una de esas dimensiones evolucionó a un ritmo distinto en los últimos 50 años, presentando fases bien definidas. En esta sección se examinan los modelos de financiamiento habitacional, la política de subsidio y su interacción con el crédito, aspectos que constituyen el objeto central de este artículo ${ }^{1}$.

\footnotetext{
${ }^{1}$ Véase una visión histórica más amplia de la política habitacional chilena en Castillo e Hidalgo (2007); MINVU (2007), y Brain, Cubillos y Sabatini (2007).
}

\section{Sistema de financiamiento}

La historia del financiamiento habitacional en Chile en el siglo XX puede dividirse en tres períodos, según los instrumentos de intermediación financiera que asignan los recursos de ahorro a la inversión inmobiliaria: i) hasta 1959; ii) de 1959 a 1976, y iii) después de 1976.

De acuerdo con Morandé (1993), el financiamiento hipotecario ocupó un lugar destacado en la política de intermediación financiera chilena en el primer período. En la década de 1930, los bonos hipotecarios -instrumentos emitidos en pesos y con tasas nominales de interés - llegaron a representar el 50\% de las ofertas de crédito del sistema bancario. Con el aumento de la inflación a partir de 1940, dichas tasas quedaron por 
debajo del incremento de los precios y se tradujeron en transferencias de ingresos de los inversionistas a los deudores hipotecarios. El mercado no resistió y el sistema redujo considerablemente la oferta de crédito.

En 1959, el gobierno encontró una solución al problema mediante la creación de incentivos tributarios para la oferta y la demanda, contenidos en el decreto con fuerza de ley $\mathrm{N}^{\circ} 2$ de 1959 (DFL2). La innovación del decreto consistió en el establecimiento de un régimen de corrección monetaria para las operaciones a largo plazo, permitiendo de ese modo que la inversión y el ahorro convivieran con tasas de inflación elevadas.

Ese mismo año se creó el Sistema Nacional de Ahorro y Préstamo (SINAP), que desempeñó un papel relevante en la captación de ahorro mediante la creación de las asociaciones de ahorro y préstamo, revitalizó la actividad habitacional y validó el sistema de índices de reajustes, que fueron la base del éxito posterior de los nuevos sistemas de financiamiento de viviendas establecidos a partir de los años setenta. La indexación de los depósitos de ahorro y del crédito hipotecario, que se mantiene hasta el día de hoy, fue de vital importancia para eliminar el riesgo inflacionario y garantizar la oferta de crédito a menor costo.
En la década de 1960 y a inicios de los años setenta, el gobierno impulsó una amplia política de subsidios para la adquisición de viviendas por parte de los sectores de bajos ingresos. De 1960 a 1969, casi 68.000 familias tuvieron acceso al subsidio para la compra de la casa propia, cifra que aumentó a casi 150.000 familias entre 1970 y 1979 (véase el gráfico 1). En solo tres años, de 1970 a 1972, más de 72.500 familias tuvieron acceso al subsidio.

El sINAP perdió su fuerza a mediados de los años setenta. Entre 1974 y 1976, el número de unidades financiadas por año (16.100) se redujo un $28 \%$ en comparación con los cuatro años anteriores $(22.400)^{2}$. Eso ocurrió porque la captación de recursos disminuyó drásticamente debido a la recesión, la pérdida de poder adquisitivo de la población y la inestabilidad política en el país. Por otra parte, se observaba un desfase entre los plazos de aplicación y los de captación, un problema ya conocido del sistema norteamericano.

En 1976 se introdujo un nuevo marco institucional mediante reformas estructurales para la liberalización de

\footnotetext{
2 Encuesta CASEN de 2009.
}

GRÁFICO 1

Chile: número de familias con acceso al crédito y al subsidioa, suma en el período 1950-2009

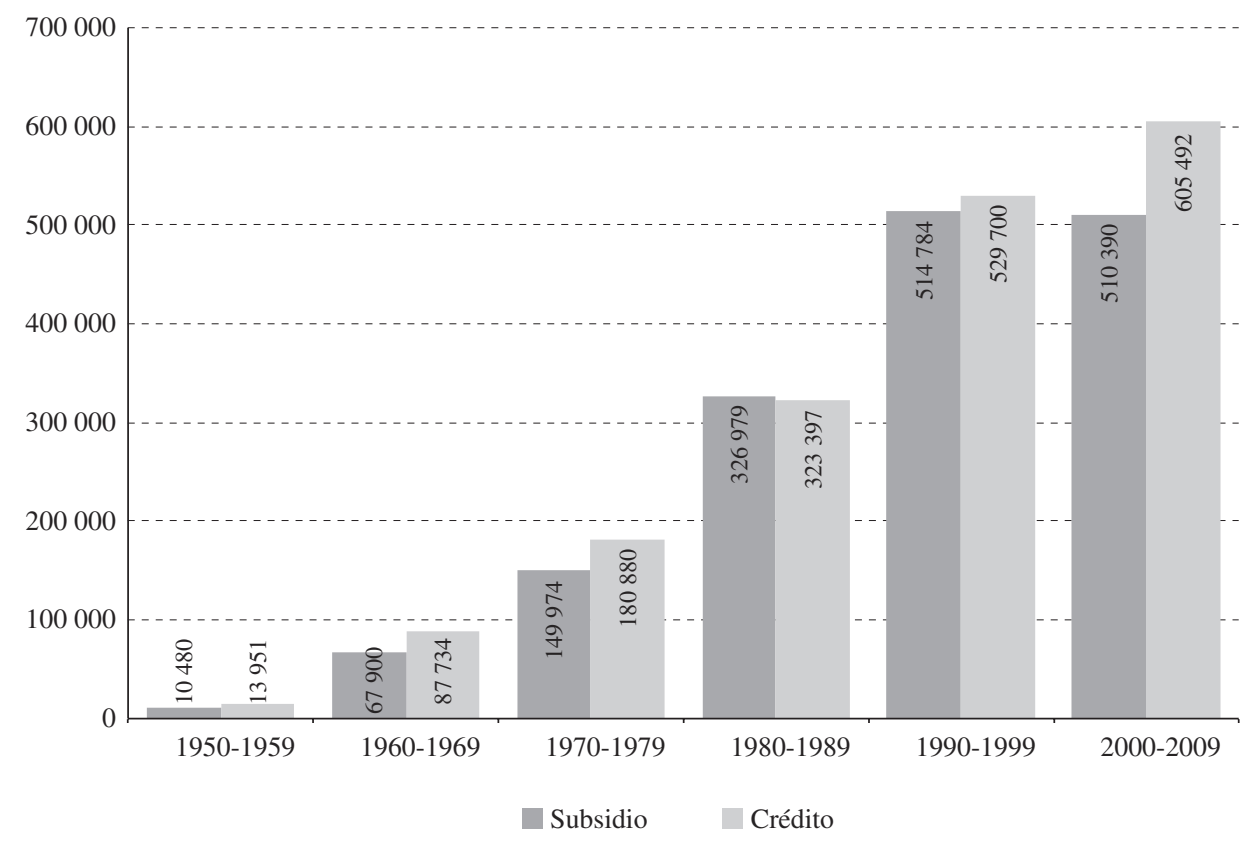

Fuente: elaboración propia sobre la base de la Encuesta de Caracterización Socioeconómica Nacional (CASEN) de 2009.

a Incluye programas de alquiler social. 
la economía, acompañadas de medidas de estabilización económica. Con eso se produjo una profunda reformulación del mercado de capitales, que a su vez tuvo repercusiones en la intermediación financiera y el crédito habitacional.

La reforma de la previsión social, a fines de 1980, constituyó otro factor importante que fomentó el mercado secundario de títulos y canalizó grandes recursos de largo plazo al financiamiento inmobiliario. De acuerdo con la Superintendencia de Pensiones, el número de cuentas de pensiones por capitalización creció rápidamente después de la reforma, pasando de cerca de 500.000 a mediados de 1981 a 5.014 millones de cuentas en diciembre de 1994. Por su parte, los activos de los fondos pasaron de 305 millones de dólares en 1981 a 21.145 millones de dólares en 1994, crecimiento que fue fundamental para ampliar la oferta global de fondos en los años ochenta y noventa, cuando el crédito inmobiliario se expandía rápidamente ${ }^{3}$.

Las cajas de ahorro, que sumaban casi 14 millones de cuentas con un patrimonio de más de 130.000 millones de dólares a fines de 2010, proporcionaron una parte del crédito concedido para la vivienda ${ }^{4}$. Esos recursos representan un activo de las familias chilenas, que puede movilizarse en el momento de la adquisición del inmueble reduciendo la necesidad de crédito. Asimismo, durante su permanencia en el sistema financiero una parte de esos recursos se aplica a la concesión de crédito inmobiliario.

En el nuevo sistema, el financiamiento de la vivienda pasó a realizarse mediante diversas combinaciones de recursos públicos y privados. El sistema se basa en la concesión de crédito a largo plazo (de 8 a 30 años) en dos modalidades: i) letras de crédito hipotecarias, emitidas al portador; o ii) mutuos hipotecarios endosables. Tanto las letras de crédito como los mutuos se expresan en una unidad de cuenta reajustable diariamente según la variación de la unidad de fomento (UF), que sigue el comportamiento del índice de precios al consumidor (IPC) y garantiza el mantenimiento de los valores reales de los préstamos. Los recursos para la adquisición de letras de crédito y mutuos provienen de fondos de pensión, empresas de seguros de vida e inversionistas privados.

Además de la hipoteca, el nuevo sistema de financiamiento habitacional se basa en otras dos fuentes de recursos: los subsidios y el ahorro previo. Los subsidios explícitos constituyen un mecanismo de transferencia de riqueza de carácter social, que canaliza recursos de

\footnotetext{
${ }^{3}$ El número de cuentas en los fondos de pensiones chilenos llegó a 8,957 millones en diciembre de 2011, mientras que los activos de los fondos sumaron 145.600 millones de dólares.

4 Datos de la Superintendencia de Bancos e Instituciones Financieras (SBIF).
}

impuestos para resolver la carencia de viviendas y reduce la necesidad de crédito.

El ahorro previo también aminora la necesidad de crédito de las familias que adquieren inmuebles y, además, los fondos que este genera se emplean en la concesión de préstamos durante el período de su formación, ampliando la disponibilidad de crédito. Según datos de la Superintendencia de Bancos e Instituciones Financieras (SBIF) de Chile, existen 3,36 millones de cuentas de ahorro previo $^{5}$ para la adquisición de viviendas, con saldos acumulados de 19.642 millones de uf y un valor acordado de 170.859 millones de UF en diciembre de $2010^{6}$. El volumen de fondos recaudados por el sistema revela, por sí solo, la importancia del ahorro previo en la formación de fondos para el crédito.

Este modelo de financiamiento habitacional permanece prácticamente igual hasta el presente. Al finalizar el régimen militar en 1992, los gobiernos democráticos mantuvieron las líneas generales del sistema y ampliaron los recursos destinados a los subsidios. En los años ochenta se concedieron subsidios a 330.000 familias, cifra que aumentó a 515.000 en la década siguiente (véase el gráfico 1). A raíz de ello y del crecimiento económico de los años noventa, el volumen del crédito también se amplió.

\section{Política de subsidios}

La política de subsidios habitacionales se creó en Chile en los años setenta y, en esencia, permanece igual hasta el día de hoy (Simian, 2010). Esa política tiene en cuenta los principios de equidad y progresividad: el acceso es universal y los subsidios son proporcionalmente mayores para la población de menores ingresos. En líneas generales, el sistema se basa en la concesión de subsidios para la demanda o la construcción y donación de viviendas. En la primera modalidad, el gobierno concede un certificado que se utiliza como forma de pago de una parte del valor de la vivienda, reduciendo la necesidad de ahorro previo y de crédito. La política de construcción y cesión de viviendas se aplica a los sectores de más bajos ingresos de la sociedad, que carecen de condiciones para formar ahorro previo u obtener crédito.

\footnotetext{
${ }^{5} \mathrm{El}$ ahorro acordado para la adquisición de una vivienda es una de las modalidades de captación de ahorro del sistema chileno. El total de cuentas de ahorro llegaba a 13,8 millones a fines de 2010, con un saldo de depósitos del valor de 2.852 millones de UF.

${ }^{6}$ El valor de la UF en diciembre de 2010 era de $\$ 21.454,91$ o 45,81 dólares. Eso significa que en diciembre de 2010 ya se habían depositado 889,75 millones de dólares para la adquisición de la casa propia de un total de 7.827 millones de dólares a ser depositados para esa finalidad.
} 
Desde mediados de la década de 1970 hasta ahora, la política habitacional chilena convivió con innumerables programas de subsidios que difieren según el área de actuación (rural o urbana), el público objetivo y el tipo de vivienda. Los principales programas de ese período fueron: i) Programa de Vivienda Básica; ii) Subsidio General Unificado (sGU); iii) Programa del Subsidio Rural; iv) Programa de Economía del Trabajo (PET), y v) Programa de Vivienda Progresiva. De acuerdo con los datos de la Encuesta CASEN de 2006, esos cinco programas representan más del $75 \%$ de los subsidios concedidos entre 1976 y 2006. Los demás programas de subsidio se refieren principalmente al alquiler social, el leasing y la adquisición de lotes urbanizados.

El Programa de Vivienda Básica se creó en 1975 y funcionó hasta la década de 2000. Se destinaba a familias residentes en zonas urbanas y rurales que carecían de viviendas, en condiciones de marginalidad habitacional y que pertenecían al primer y el segundo quintiles de la distribución del ingreso. En el programa se definió la pauta del financiamiento habitacional para las personas de bajos ingresos en Chile mediante la combinación de ahorro previo, subsidio y crédito. El subsidio medio equivalía al $70 \%$ del precio de la vivienda ${ }^{7}$.

El Subsidio General Unificado, creado en 1978, se destina a familias de ingresos medio-bajos que no son propietarias de viviendas, pero poseen capacidad de pago suficiente para obtener crédito bancario. La familia debe demostrar la disposición al pago de la casa, reflejada en el ahorro previo depositado en una cuenta de ahorro vinculada (Cuenta de Ahorro a Plazo para la Vivienda). Por medio de ese sistema es posible adquirir una casa de carácter definitivo, nueva o usada, en una zona urbana o rural.

El Programa de Subsidio Rural comenzó a funcionar en 1980 y se destinó a familias residentes en zonas rurales en condiciones de marginalidad habitacional, propietarias de un terreno en la zona rural o con derechos sobre él. Se exigía el aporte del terreno (otra forma de ahorro previo) $\mathrm{y}$ el resto se financiaba mediante un crédito bancario.

El Programa de Economía del Trabajo (PET) se creó en 1985 para atender a las familias sin casa propia pertenecientes a grupos sociales organizados, preferiblemente ligados a categorías profesionales o a asociaciones de trabajadores. Al igual que el programa de vivienda básica, el PET asistió a las familias de las áreas urbana y rural por medio de la tríada ahorro previo, subsidio y crédito.

\footnotetext{
${ }^{7}$ Véanse más detalles del programa en MINVU (2007).
}

El Programa de Vivienda Progresiva entró en funcionamiento en 1990 para atender a las familias sin viviendas que convivían con otras familias o vivían en condiciones de marginalidad habitacional. Se dio prioridad a las familias del primer quintil de la distribución del ingreso. Las viviendas de este programa se concibieron para ser construidas en etapas. La primera etapa preveía una vivienda de $13 \mathrm{~m}^{2}$ en un terreno de $100 \mathrm{~m}^{2}$. El terreno debía tener urbanización completa y la casa debía contar con infraestructura sanitaria y una habitación. Después de esa primera etapa, la familia podía terminar la casa por cuenta propia o solicitar apoyo estatal para la etapa siguiente. Para acceder al programa era necesario tener ahorro previo y el resto del financiamiento se realizaba mediante subsidio estatal y crédito hipotecario otorgado por el Servicio de Vivienda y Urbanismo (SERVIU).

Estos programas se revisaron y fueron sustituidos por otros nuevos a partir de la década de 2000. Conforme señala Simian (2010), los principales cambios consistieron en la revisión de los valores de referencia y la extinción de la modalidad de construcción de viviendas para donación. Los dos principales programas de subsidio establecidos en ese período fueron el Fondo Solidario de Vivienda, de 2001, y el subsidio habitacional, de 2004. No obstante, cabe mencionar que con esos nuevos programas se mantuvo el modelo de financiamiento mediante ahorro previo, subsidio y crédito.

Como destaca Simian (2010), la política de subsidio y su interacción con los mecanismos de financiamiento fueron fundamentales para aumentar las inversiones en viviendas en Chile, debido a que:

"El subsidio habitacional es un mecanismo de subsidio a la demanda que está pensado para subsanar el problema de asimetría de información, reduciendo la necesidad de crédito y evitando asî un excesivo riesgo para instituciones financieras que no prestarían si no hubiese un subsidio de por medio" (Simian, 2010, pág. 288).

De ese modo, el subsidio redujo la necesidad de crédito y minimizó los riesgos de financiamiento para los sectores de la población de bajos ingresos, aumentando la oferta de crédito. Por otra parte, el subsidio habitacional se concede mediante la contrapartida de un ahorro previo $^{8}$. De acuerdo con Domínguez Vial y Nieto de

\footnotetext{
${ }^{8}$ En el sistema chileno de subsidio habitacional el ahorro previo es una condición obligatoria, ya sea como aporte en dinero o mediante la propiedad del terreno. Se hace excepción de este requisito en el caso de las familias que viven en situación de extrema pobreza, las que reciben atención prioritaria y directa del Estado. Simian (2010, pág. 286) presenta los programas de subsidio y el ahorro previo requerido para la obtención del subsidio en el período comprendido entre 1974 y 2008.
} 
los Ríos (1993), este subsidio constituye también una forma de medir el esfuerzo inicial y la capacidad de generar ahorro, reduciendo la asimetría de información.

Los datos de la Encuesta CASEN de 2009 muestran la relación entre el crédito y el subsidio en Chile. Hasta 2009, 1 millón 633 mil familias chilenas obtuvieron subsidios para la adquisición de viviendas (véase el cuadro 1), de las cuales 1 millón 276 mil contaron también con crédito para el financiamiento de la compra (el $32 \%$ de las familias chilenas). Mientras que 358.000 familias solo recurrieron al subsidio, otras 527.000 familias tuvieron acceso al crédito, pero no contaron con recursos provenientes de subsidio para la adquisición de la vivienda. Más del $70 \%$ de las familias que obtuvieron crédito (1,8 millones) accedieron al subsidio, de modo que — como argumenta Simian (2010)— el subsidio parece incrementar las probabilidades de obtener crédito. Sin embargo, cerca del $62 \%$ de las familias chilenas no tuvieron acceso al crédito ni al subsidio (3,5 millones $)^{9}$.

En el cuadro 2 se presenta el número de familias que tuvieron acceso a programas de crédito o de subsidio en el período de 1976 a 2009. Se observa que en ese lapso, más de 3,1 millones de familias chilenas adquirieron una vivienda. La mitad de ellas accedieron al crédito y el $35 \%$ al crédito y al subsidio. Por otra parte, el $40 \%$

\footnotetext{
${ }^{9}$ La elevada magnitud de este número se debe a que comprende a todos los jefes de familia, incluso aquellos que pagan alquileres, viven en inmuebles cedidos por el empleador o cohabitan con otras familias. También incluye a las familias que compraron inmuebles mucho antes de las reformas instituidas en los actuales sistemas de financiamiento y de subsidio.
}

no tuvieron acceso a ningún tipo de programa para la compra de la vivienda, mientras que el $72 \%$ de las familias con acceso a crédito obtuvieron un subsidio. Estos datos refuerzan la idea anterior de que el acceso al crédito parece estar en gran medida condicionado por el acceso al subsidio.

CUADRO 1

Chile: familias que recibieron crédito o subsidio para la adquisición de viviendas, hasta 2009

\begin{tabular}{llrrr}
\hline & \multicolumn{3}{c}{ Subsidio } & \multirow{2}{*}{ Total } \\
\cline { 3 - 4 } & & \multicolumn{1}{c}{ No } & \multicolumn{1}{c}{ Sí } & \\
\hline \multirow{2}{*}{ Crédito } & No & 3490215 & 357661 & 3847876 \\
Total & Sí & 527177 & 1275796 & 1802973 \\
\hline
\end{tabular}

Fuente: elaboración propia sobre la base de la Encuesta de Caracterización Socioeconómica Nacional (CASEN) de 2009.

CUADRO 2

Chile: familias que recibieron crédito o subsidio para la adquisición de viviendas, 1976-2009

\begin{tabular}{llrrr}
\hline & & \multicolumn{2}{c}{ Subsidio } & \multirow{2}{*}{ Total } \\
\cline { 3 - 4 } & & \multicolumn{1}{c}{ No } & \multicolumn{1}{c}{ Sí } & \\
\hline \multirow{2}{*}{ Crédito } & No & 1263972 & 323676 & 1587648 \\
Total & Sí & 443299 & 1116506 & 1559805 \\
\hline
\end{tabular}

Fuente: elaboración propia sobre la base de la Encuesta de Caracterización Socioeconómica Nacional (CASEN) de 2009.

\section{III}

\section{Subsidios, crédito e inversión inmobiliaria}

En la visión general sobre el papel de los subsidios habitacionales destaca su efecto permanente en el flujo de ingresos y la riqueza de las familias ${ }^{10}$. Sin embargo,

\footnotetext{
${ }^{10}$ De acuerdo con el Ministerio de Vivienda y Urbanismo (MINVU): "El subsidio de la vivienda constituye una transferencia monetaria importante del Estado hacia los hogares seleccionados como asignatarios. Al financiarse una parte de un bien de uso durable como la vivienda, el subsidio habitacional genera una renta por la parte del costo de la casa que cubre. Esto es una renta que se manifiesta como ahorro en el gasto mensual del alojamiento, siendo un aporte permanente del
}

en este artículo se parte de una hipótesis más amplia: visto que el subsidio es una transferencia instantánea de recursos usada para pagar parte del valor del inmueble, se puede afirmar que él influye en las condiciones generales de financiamiento y, por lo tanto, afecta a las decisiones de los bancos con respecto a la oferta de crédito.

subsidio estatal al ingreso y calidad de vida de los sectores pobres, mientras las familias hagan uso de la vivienda subsidiada" (MINVU, 2007, pág. 235). 


\section{Subsidio habitacional y rendimiento de los bancos}

El financiamiento habitacional es un contrato que supone cinco elementos: el monto del préstamo $(B)$, la tasa de interés del financiamiento $\left(r^{*}\right)$, la garantía subsidiaria (colateral) $(C)$-activo real usado como garantía del préstamo (hipoteca) — , el valor subsidiado $(S)$ y el valor de la entrada $(E)$. La hipoteca se ejecuta en caso de incumplimiento del contrato. En cuanto al financiamiento habitacional, el valor de la garantía equivale al valor del inmueble. Para simplificar, se asume que en el contrato se establecen dos períodos de tiempo: mientras que en el período $t$ tiene lugar el endeudamiento, en $t+1$ el prestatario debe devolver el principal y los intereses.

Se asume que el valor del préstamo tomado en el período inicial corresponde a una parte de la garantía, menos el monto del subsidio. Esa relación se establece en la ecuación (1), en que $\lambda$ es el porcentaje del valor del inmueble que se financia, ya descontado el subsidio $(-0<\lambda \leq 1)$. El resto $(1-\lambda)$ equivale a la parte de ahorro previo exigida por el banco para el financiamiento - la entrada del contrato $(E)$. Se asume que $0 \leq S \leq C$.

$$
C=B+E+S, B=\lambda \cdot(C-S) \text { y } E=(1-\lambda) \cdot(C-S)
$$

El cumplimiento del contrato depende de una condición financiera básica —ecuación (2) — y de la distribución de la probabilidad de cumplimiento. La condición financiera para el pago impone que el valor de la deuda más los intereses no supere el valor de la garantía, pues en caso contrario sería más ventajoso para el prestatario no pagar la deuda y entregar al banco la garantía subsidiaria en el vencimiento del plazo.

$$
B+B \cdot r^{*}<C
$$

Satisfecha la condición (2), el contrato se cumplirá o no conforme con las condiciones de interés y los recursos de que dispone el prestatario. Se define $p$ como la probabilidad de cumplimiento del contrato de financiamiento: en el período $t+1$ cada contrato tiene una probabilidad $p$ de ser pagado y $(1-p)$ de no ser pagado. La probabilidad $p$ depende de los recursos de las familias $(w)$ y de la tasa de interés del financiamiento habitacional, como se propone en la ecuación (3).

$$
p=f\left(w, r^{*}\right), p \in[0,1]
$$

Se asume que el aumento de la tasa de interés del financiamiento habitacional reduce la probabilidad de cumplimiento del contrato, mientras que el incremento de la riqueza de las familias la acrecienta ${ }^{11}$. Las segundas derivadas son, por hipótesis, positivas.

$$
\frac{\partial p}{\partial r^{*}}<0, \frac{\partial p^{2}}{\partial^{2} r^{*}}>0 \quad \text { y } \quad \frac{\partial p}{\partial w}>0 \frac{\partial p^{2}}{\partial^{2} w}>0
$$

El rendimiento de los bancos depende de los parámetros del contrato y de la probabilidad de cumplimiento. Si el prestatario respeta el contrato, el banco gasta el monto prestado y recibe esa suma incrementada por el pago de los intereses del financiamiento. Si el prestatario no respeta el contrato, el banco pierde la cantidad prestada y recibe la garantía subsidiaria. En el gráfico 2 se observa el rendimiento de los bancos en cada caso.

GRÁFICO 2

\section{Posible rendimiento del préstamo} inmobiliario

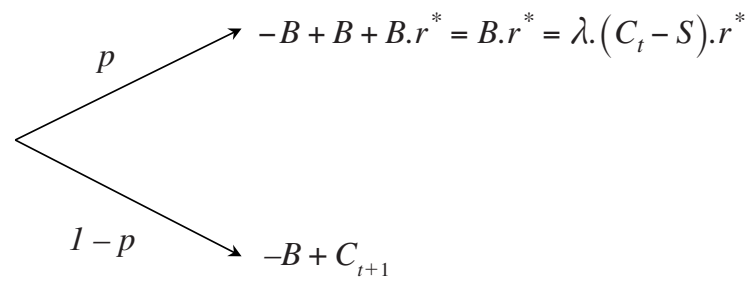

Fuente: elaboración propia.

Para simplificar, se asume que el valor de la garantía subsidiaria en $t+1$ es igual al valor de la garantía subsidiaria en $t$, o en otras palabras, no se tiene en cuenta la valorización del inmueble a lo largo del tiempo o la tasa de depreciación $(\delta)$ en el período.

$$
C_{t+1}=C_{t}=C
$$

Teniendo en cuenta ambas posibilidades, cumplimiento e incumplimiento, el rendimiento esperado del banco (П) es una función de la tasa de interés del financiamiento, del monto del subsidio y de la suma prestada.

${ }^{11}$ Cabe recordar que, por construcción, $p$ está limitado al intervalo entre cero (0) y uno (1). Cuando $p$ alcanza el valor 1 , la derivada de $p$ en relación con $w$ se vuelve nula. 


$$
\Pi\left(r^{*}, S, B\right)=p \cdot B \cdot r^{*}+(1-p) \cdot(C-B)
$$

La tasa de rendimiento esperada de los bancos se define como el rendimiento esperado dividido por la suma prestada:

$$
\rho\left(r^{*}, S, B\right)=\Pi\left(r^{*}, S, B\right) / B=p \cdot r^{*}+(1-p) \cdot(C / B-1)
$$

Se asume que los bancos procuran obtener las mayores ganancias posibles, de modo que la tasa de interés utilizada en el financiamiento será aquella que maximiza el rendimiento esperado de los bancos, conforme propusieron Stiglitz y Weiss (1981). Al formular la derivada de la tasa de rendimiento esperado de los bancos con respecto a la $r^{*}$, y tener en cuenta la ecuación (3), se obtiene:

$$
\frac{\partial \rho}{\partial r^{*}}=p_{r}^{\prime} \cdot r^{*}+p-p_{r}^{\prime} \cdot(C / B-1)
$$

Esa relación puede ser mayor o menor que cero (0) dependiendo de la tasa de interés del financiamiento. Como $p>0, p_{r}^{\prime}<0$ - premisa asumida en la ecuación (4) - y $C \geq B$, cuando la tasa de interés tiende a cero (0) la derivada es positiva. Por el contrario, cuando $r^{*}$ tiende al infinito la derivada es negativa.

$$
\lim _{r^{*} \rightarrow 0} \partial \rho / \partial r^{*}>0 \text { y } \lim _{r^{*} \rightarrow \infty} \partial \rho / \partial r^{*}<0
$$

Para establecer la tasa de interés que maximiza la tasa de rendimiento de los bancos basta igualar la derivada anterior a cero (0). Esa condición supone que:

$$
p_{r}^{\prime} \cdot r^{*}=p_{r}^{\prime} \cdot(C / B-1)-p \text { o } r^{*}=\frac{C}{B}-1-\frac{p}{p_{r}^{\prime}}
$$

En consecuencia, existe una tasa de interés máxima que es positiva. Si la tasa de interés es mayor que $r^{*}$, la tasa de rendimiento de los bancos no es la máxima ${ }^{12}$. El monto del subsidio concedido para la compra de un inmueble influye en el rendimiento esperado de los bancos. A medida que aumenta el valor del subsidio disminuye el monto prestado por el banco, porque una

12 Para confirmar que $r^{*}$ es un punto máximo, basta con calcular la segunda derivada de la tasa de rendimiento de los bancos respecto de la tasa de interés del financiamiento.

$\frac{\partial \rho^{2}}{\partial^{2} r^{*}}=p_{r}^{\prime \prime} \cdot r^{*}+2 \cdot p_{r}^{\prime}-p_{r}^{\prime \prime} \cdot\left(\frac{C}{B}-1\right)=2 \cdot p_{r}^{\prime}+p_{r}^{\prime \prime} \cdot\left(\frac{B\left(1+r^{*}\right)-C}{B}\right)<0$ parte del valor del inmueble fue pagada por el gobierno. Al sustituir la definición de $B$ de la ecuación (1) en (7), se obtiene:

$$
\begin{gathered}
\rho\left(r^{*}, S, B\right)=p \cdot r^{*}+(1-p) \cdot(C / \lambda \cdot(C-S)-1) \\
\quad=p \cdot r^{*}+(1-p) \cdot\left(\frac{C \cdot(1-\lambda)+\lambda \cdot S}{\lambda \cdot(C-S)}\right)
\end{gathered}
$$

La derivada de la tasa de rendimiento esperada de los bancos en relación con el subsidio es:

$$
\frac{\partial \rho}{\partial S}=\frac{C \cdot \lambda \cdot(1-p)}{[\lambda .(C-S)]^{2}}>0
$$

Eso significa que cuanto mayor sea el subsidio -mantenidas las demás variables constantes-, mayor será la tasa de rendimiento esperada de los bancos. El análisis de la segunda derivada de la tasa de rendimiento con respecto al subsidio muestra que la tasa de rendimiento se incrementa a tasas crecientes conforme aumenta el monto del subsidio.

$$
\frac{\partial \rho^{2}}{\partial^{2} S}=\frac{2 \cdot C \cdot \lambda^{2} \cdot(1-p)}{[\lambda \cdot(C-S)]^{3}}>0
$$

Otro aspecto importante es que el subsidio influye en la tasa de financiamiento $r^{*}$ que maximiza el rendimiento de los bancos -ecuación (8). Debido a que $B$ contiene el valor del subsidio, un cambio en ese valor influye en la tasa de equilibrio. Al formular la derivada de la ecuación (8) con respecto a $S$, se obtiene:

$$
\left.\frac{\partial r^{*}}{\partial S}\right|_{\rho \max }=\frac{C \cdot \lambda}{[\lambda .(C-S)]^{2}}>0
$$

Así, cuanto mayor sea el subsidio, mayor será la tasa de financiamiento, pues el aumento del valor del subsidio desplaza a la curva de rendimiento esperada de los bancos (véase el gráfico 2). A igual tasa de interés, un subsidio mayor supone también un rendimiento mayor. Sin embargo, el incremento del subsidio supone que es mayor la tasa de interés del financiamiento que maximiza el rendimiento de los bancos.

\section{Subsidio habitacional y mercado de crédito}

Así como el subsidio afecta positivamente al rendimiento de los préstamos bancarios para el financiamiento inmobiliario, también influye en la oferta de crédito para la adquisición de una vivienda $\left(L^{S}\right)$. A fin de entender 
esa influencia del subsidio vale la pena recurrir al gráfico propuesto por Stiglitz y Weiss (1981). Partiendo de la coordenada cartesiana de $L^{S}$ por $\Pi$ del gráfico 3 , se observa que la tasa de interés que maximiza el rendimiento esperado del banco determina el punto final de la oferta de crédito de los bancos. La cantidad de crédito ofrecido por los bancos también depende del volumen de fondos para el financiamiento que hay en la economía, que es una variable exógena designada por $M$. En el primer cuadrante del gráfico se muestra la relación de la oferta de crédito con la tasa de interés del financiamiento. Se observa que dicha oferta es creciente en relación con la tasa de interés hasta el punto $r^{*}$. A partir de ese punto la oferta disminuye conforme aumenta la tasa de interés.

En este sistema, la concesión del subsidio desplaza a la curva de rendimiento esperado de los bancos (cuadrante $\Pi$ por $r$ ), lo que supone un incremento de la oferta de crédito (cuadrante $\Pi$ por $L^{S}$ ). Estos cambios afectan a la relación entre la tasa de interés del financiamiento inmobiliario y la oferta de crédito: se observa el movimiento ascendente de la curva de la oferta de crédito en el cuadrante $L$ por $r$. Ese desplazamiento significa que, con la misma tasa de interés $\left(r^{*}\right)$, la ampliación del subsidio se traduce en una mayor oferta de crédito. Se observa además la expansión de la cantidad de crédito ofrecida debido al aumento de la tasa de interés del financiamiento habitacional de $r^{*}$ a $r^{* *}$.

$\mathrm{Al}$ acrecentarse los fondos para el financiamiento de la inversión inmobiliaria se incrementa también la oferta de crédito. Sin embargo, esa expansión no afecta a la tasa de interés del financiamiento, que maximiza el rendimiento esperado. En consecuencia, ese efecto debe verse como un movimiento ascendente de la curva de oferta de crédito.

Por último, cabe analizar el efecto del subsidio, y de otros parámetros que definen el contrato de financiamiento inmobiliario, en las decisiones de las familias de tomar préstamos para la compra de la casa propia. Sobre la base de los modelos de Stiglitz y Weiss (1981), se asume que las familias tienen una función de utilidad $U(w)$ que responde al nivel de riqueza. La utilidad marginal es positiva y decreciente: $U^{\prime}>0, U^{\prime \prime}<0$. La decisión de tomar recursos prestados para la adquisición de un inmueble deriva de la comparación realizada por la familia de las utilidades esperadas ligadas a: i) la opción de inversión sin riesgo; ii) la solicitud de un préstamo, o iii) el autofinanciamiento de la vivienda.

En el primer caso, la familia no adquiere el inmueble y paga un alquiler por la vivienda. Todos los recursos familiares se asignan a activos financieros sin riesgo. De

GRÁFICO 3

Efecto del subsidio en la oferta de crédito

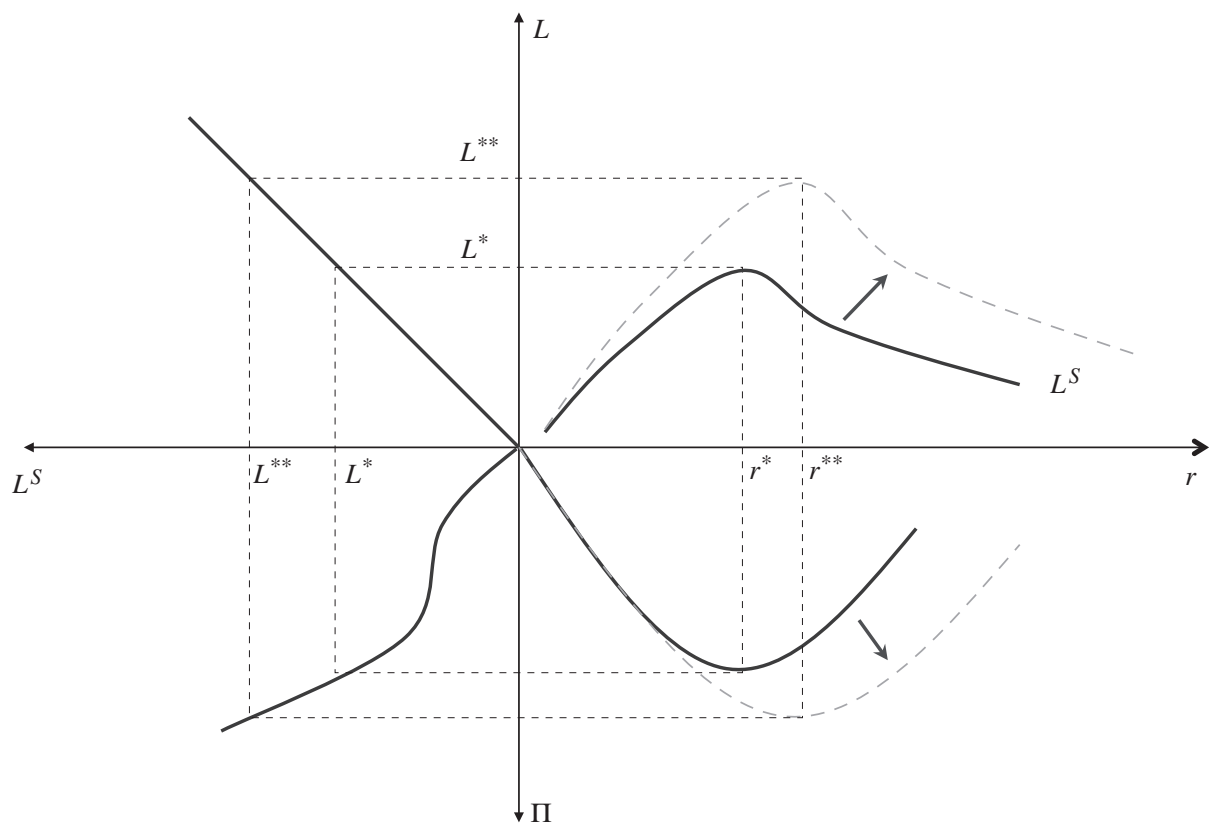

Fuente: elaboración propia sobre la base de Ana Lelia Magnabosco, "A política de subsídios habitacionais e sua influência na dinâmica de investimento imobiliário e no déficit de moradias do Brasil e do Chile", São Paulo, Pontificia Universidad Católica de São Paulo, 2011. 
ese modo, la utilidad esperada de la opción i) se define como la utilidad vinculada al valor de la riqueza inicial $\left(w_{0}\right)$ de la familia, capitalizado por la tasa de rendimiento de la inversión segura $(r)$, menos el pago del alquiler.

$$
U_{a} \equiv U\left(w_{0} \cdot(1+r)-R\right)
$$

Si la familia accede al crédito inmobiliario (situación ii), la utilidad esperada corresponde a la ecuación (10). Ese valor es la suma, ponderada por las probabilidades, de las utilidades en caso de pago o falta de pago de la deuda. Cuando la deuda se paga, la utilidad de la familia corresponde al valor de la riqueza inicial menos el pago de la entrada para la adquisición de la casa propia, capitalizado por la tasa de interés de mercado, descontados el principal y el servicio del préstamo inmobiliario y sumado el valor del inmueble. Cuando la deuda no se paga, la utilidad corresponde al valor de la riqueza menos la entrada para la adquisición de la casa propia, capitalizado por la tasa de interés de mercado, descontado el valor del inmueble que se devolvió al banco.

$$
\begin{gathered}
U_{b} \equiv U\left(\left(w_{0}-E\right) \cdot(1+r)-B \cdot\left(1+r^{*}\right)+C\right) \cdot p+ \\
U\left(\left(w_{0}-E\right) \cdot(1+r)-C\right) \cdot(1-p)
\end{gathered}
$$

En el caso del autofinanciamiento de la vivienda (situación iii), la utilidad esperada corresponde a la expresión (11). Ese valor es prácticamente igual al de la ecuación (9), con la diferencia de que en lugar de restar el valor del alquiler se descuenta el valor del inmueble multiplicado por $r$.

$$
U_{c} \equiv U\left(\left(w_{0}-C\right) \cdot(1+r)+C\right)=U\left(w_{0} \cdot(1+r)-C . r\right)
$$

De la comparación directa de las ecuaciones (9) y (11) surge la relación que define la opción entre la inversión segura o el autofinanciamiento del inmueble. La utilidad esperada del autofinanciamiento es mayor que la utilidad esperada de la inversión segura cuando el alquiler $R$ es mayor que el valor del inmueble multiplicado por la tasa de interés de la inversión segura $(C . r)$, que es el monto del ingreso financiero que se deja de obtener porque el dinero se invirtió en el inmueble ${ }^{13}$.

${ }^{13}$ Esta relación muestra que en mercados con un valor de alquiler reprimido o una tasa de interés de la inversión segura muy elevada se desincentiva a las familias a autofinanciar sus inmuebles.
El análisis de la decisión de tomar un préstamo requiere la comparación de las funciones de utilidad esperada (10) y (11). Para ello se divide la ecuación (10) en dos partes: la primera referida al valor que se obtiene cuando el préstamo se paga (subíndice 1) y la segunda, al valor obtenido en caso de incumplimiento (subíndice 2). La primera parte de la ecuación (10) puede escribirse de la siguiente manera:

$$
U_{b 1} \equiv U\left(w_{0} \cdot(1+r)-C \cdot r+(B+S) \cdot(1+r)-B \cdot\left(1+r^{*}\right)\right)
$$

Comparando el argumento de esta función con el de la ecuación (11), se observa que la utilidad esperada del autofinanciamiento puede ser tanto mayor como menor que la utilidad esperada del préstamo (en caso de cumplimiento). Cuando la siguiente expresión es positiva, la utilidad esperada del préstamo (en caso de cumplimiento) es menor que la utilidad esperada del autofinanciamiento:

$$
(B+S) \cdot(1+r)-B \cdot\left(1+r^{*}\right)>0
$$

Esto ocurre cuando el valor del subsidio, capitalizado por la tasa de interés de la inversión segura, es mayor (en módulo) que el valor de la deuda multiplicado por la diferencia entre la tasa de interés de la inversión segura y la tasa de interés del financiamiento inmobiliario. En caso de no haber subsidio, seguramente $U_{b 1}<U_{c}$. Conforme aumenta el valor del subsidio, la utilidad esperada del préstamo tiende a ser mayor que la utilidad esperada del autofinanciamiento. Lo mismo ocurre cuando la tasa de financiamiento inmobiliario se aproxima a la tasa de inversión segura.

La segunda parte de la ecuación (10), vinculada al subíndice 2, puede escribirse de la siguiente manera:

$$
U_{b 2} \equiv U\left(w_{0} \cdot(1+r)-C-E \cdot(1+r)\right)
$$

Al comparar el argumento de esta función con el de la ecuación (11), se aprecia que la utilidad esperada del autofinanciamiento también puede ser mayor o menor que la utilidad esperada del préstamo en caso de incumplimiento. La condición es la siguiente: $U_{c}$ es mayor que $U_{b 2}$ cuando $C+E .(1+r)$ es mayor que $C . r$. Esto ocurre cuando la tasa de interés $r$ es menor que la relación entre $(C+E)$ y $(C-E)$, es decir, cuando la tasa de interés de la inversión segura no es muy elevada. Por ejemplo, en el caso de que $E$ fuera igual a cero (0), la tasa 
de interés límite sería del 100\% entre los dos períodos. Si se trata de una tasa de interés mayor del $100 \%$ entre dos períodos ${ }^{14}$, la utilidad esperada del préstamo tiende a ser mayor que la del autofinanciamiento, conforme disminuye el valor de la entrada.

En resumen, la utilidad esperada de la solicitud de un préstamo puede ser mayor o menor que la utilidad esperada del autofinanciamiento. Sin embargo, es sabido que los contratos de financiamiento con un subsidio elevado y una entrada reducida aumentan la utilidad esperada de la opción por un préstamo. Lo mismo ocurre cuando la tasa de interés de financiamiento se aproxima a la tasa de interés de la inversión segura. Por otra parte, las tarifas de alquiler reducidas o las tasas de interés de la inversión segura elevadas reprimen tanto el autofinanciamiento como el préstamo para la adquisición de la casa propia.

El nivel de recursos también incide en la decisión de las familias. En el caso de las familias muy pobres, con una riqueza inicial $w_{0}$ escasa, el valor de la entrada $(E)$ impide el ingreso en el mercado de crédito. Tampoco queda la opción del autofinanciamiento, pues si la riqueza inicial es inferior al valor de la entrada también será inferior al valor del inmueble. Los escasos recursos de esas familias se aplican a la inversión segura y esto se traduce en el alquiler de la vivienda.

Con respecto a las familias cuya riqueza inicial es mayor que el valor del inmueble, se supone - por una cuestión de progresividad - que las viviendas demandadas no cuentan con subsidio estatal. En este caso, como ya se señaló, la utilidad del préstamo es seguramente menor que la del autofinanciamiento en caso de pago de la deuda $\left(U_{b 1}<U_{c}\right)$. En caso de falta de pago de la deuda, para que $U_{b 2}$ sea menor que $U_{c}$, el valor del inmueble demandado por la familia debe ser mayor que la mitad del valor de la deuda capitalizada por la tasa de interés de la inversión segura. De ser así, se optará por el autofinanciamiento de la vivienda. Pero incluso si esta última condición no se verifica, cabe recordar que la probabilidad de falta de pago disminuye conforme crece la riqueza de las familias (véase la ecuación (4)). Por ese motivo, la decisión de autofinanciar el inmueble propio se vuelve más ventajosa a medida que aumenta la riqueza inicial de las familias. El préstamo para la adquisición

\footnotetext{
${ }^{14}$ Este es un nivel común en los planes de financiamiento inmobiliario. La tasa de interés entre dos períodos es el valor total de los intereses pagados en un financiamiento sobre el valor del préstamo. En un plan de financiamiento con prestación constante - por ejemplo, por un período de 30 años y una tasa de interés de un $9 \%$ anual- la tasa de interés entre los dos períodos sería del $192 \%$. Si la tasa de interés fuera del $6 \%$ al año, la tasa de interés entre los dos períodos sería del 118\%.
}

de la casa propia es, por lo tanto, una alternativa típica de la clase media.

Una consecuencia directa de lo descrito anteriormente es que los subsidios influyen en la demanda de crédito. $\mathrm{Al}$ incrementarse el valor de los subsidios, se acrecienta la utilidad del préstamo, que supera entonces la utilidad del autofinanciamiento para algunas familias. Por otra parte, el aumento del subsidio reduce los valores del financiamiento y de la entrada y amplía de ese modo el conjunto de familias que pasan a solicitar y acceder al crédito. Así, los subsidios tienen un efecto directo y positivo en la demanda de crédito.

\section{El subsidio habitacional y la dinámica del mercado inmobiliario}

El modelo dinámico de inversión habitacional sigue la formulación propuesta por Garcia y Rebelo (2002), que se basó en Muth (1960) y Tobin (1969). En este modelo, la economía comprende $N_{t}$ familias que crecen a una tasa constante $n$. En el instante $t$, la demanda de inmuebles de la familia representativa es $k_{t}^{d}$ y depende de la riqueza $\left(w_{t}\right)$ y del valor del alquiler $\left(R_{t}\right)$. La demanda de inmuebles corresponde a la ecuación (12):

$$
k_{t}^{d}=f\left(w_{t}\right)+g\left(R_{t}\right)
$$

Se presupone que $\partial k_{t}^{d} / \partial w_{t}>0$ y $\partial k_{t}^{d} / \partial R_{t}<0$, es decir, que la variación de la demanda de inmuebles con respecto a la riqueza es positiva y que la variación de la demanda con relación al alquiler es negativa. Por conveniencia, se supone que la función $g\left(R_{t}\right)$ es lineal: $g\left(R_{t}\right)=-\beta . R_{t}, \beta>0$. En el corto plazo, la oferta de inmuebles es fija y está dada por la ecuación (13).

$$
k_{t}^{s}=k_{t}^{0}=k_{t}
$$

El valor del alquiler está determinado por el equilibrio entre la demanda y la oferta:

$$
R_{t}=\frac{f\left(w_{t}\right)-k_{t}}{\beta}
$$

Para analizar el comportamiento de los inversionistas, se define la rentabilidad de los emprendimientos inmobiliarios. De acuerdo con Tobin (1969), $q_{t}$ se define como la razón entre el precio de mercado del inmueble $\left(p m_{t}\right)$ y el costo de reposición de una unidad de capital habitacional $\left(c_{t}\right)$. Asumiendo la hipótesis de que el costo 
de construcción es constante e igual a uno (1), $q_{t}$ se vuelve igual al precio de mercado de los inmuebles, que varía de acuerdo con la rentabilidad neta de la depreciación proporcionada por el ingreso del alquiler del activo.

$$
q_{t}=\frac{p m_{t}}{c_{t}}=p m_{t}
$$

El rendimiento del activo inmobiliario entre dos períodos tiene tres componentes: la valorización patrimonial $\dot{q}_{t}$, el ingreso del alquiler $\left(R_{t}\right)$ y la depreciación física $(\delta)$ del activo, que es una proporción del valor del inmueble $q_{t}$. La tasa de rendimiento $\left(r^{K}\right)$ se define como la relación entre el rendimiento y el precio del activo.

$$
r^{K} \equiv \frac{\dot{q}_{t}+R_{t}-\delta . q_{t}}{q_{t}}
$$

Al reordenar la expresión (15) se llega a:

$$
\dot{q}_{t}=\left(r^{K}+\delta\right) \cdot q_{t}-R_{t}
$$

Al sustituir las expresiones (12) y (13) en la ecuación (16), se obtiene la ecuación dinámica de $q_{t}$ :

$$
\dot{q}_{t}=\left(r^{K}+\delta\right) \cdot q_{t}-\frac{f\left(w_{t}\right)-k_{t}}{\beta}
$$

Para completar el modelo es necesario observar la variación de la cantidad de capital habitacional en el tiempo. Por definición, la cantidad de capital en $t$ es igual al capital en $t-1$, menos la depreciación del capital en $t$, sumada la inversión: $\dot{K}_{t}=I_{t}-\delta . K_{t}$. Al dividir ambos lados de la ecuación entre el número de familias $\left(N_{t}\right)$, y teniendo en cuenta que $\dot{k}_{t}=\dot{K}_{t} / N_{t}-n \cdot k_{t}$ e $i_{t}=I_{t} / N_{t}$, se obtiene:

$$
\dot{k}_{t}=i_{t}-(n+\delta) \cdot k_{t}
$$

El racionamiento del crédito se introduce en el modelo general de dinámica inmobiliaria por medio de la función de inversión de las familias $\left(i_{t}\right)$. Esta función responde a la cantidad de crédito ofrecida por los bancos $\mathrm{y}$ al precio de los inmuebles, y se define por la suma de la inversión realizada por las familias clasificadas en tres clases según su nivel de ingresos. Las clases $a$ y $c$ reúnen, respectivamente, a las familias muy ricas y muy pobres. Las familias de riqueza media pertenecen a la clase $b$.
Las familias muy pobres, cuya riqueza es inferior al valor de la entrada del inmueble, no tienen acceso al crédito. En este caso, la riqueza también es menor que el valor del inmueble. Por consiguiente, esas familias no tienen condiciones de autofinanciamiento y pagan un alquiler. La inversión inmobiliaria para ese sector de la población es realizada por terceros, o sea, por inversionistas que procuran el rendimiento del alquiler. Para ese grupo, vale la condición de arbitraje propuesta por Garcia y Rebelo (2002). Esto significa que la inversión para las familias de la clase $c$ depende de la relación entre el precio de mercado del inmueble y el costo de reposición $\left(q_{t}\right)$, según se expresa mediante la ecuación (19). Se asume que $\theta_{c}>0$, o sea, cuanto mayor sea el precio de mercado de los inmuebles para un determinado costo de construcción, mayor será la inversión habitacional.

$$
i_{t}^{c} \equiv i^{c}\left(q_{t}\right)=\theta_{c} \cdot q_{t}, \quad \theta_{c}>0
$$

Las familias muy ricas no participan en el mercado del crédito debido a la ventaja que conlleva el autofinanciamiento de la casa propia. Para esas familias, la inversión también depende solo de la razón entre el precio del inmueble y el costo de construcción.

$$
i_{t}^{a} \equiv i^{a}\left(q_{t}\right)=\theta_{a} \cdot q_{t}, \quad \theta_{a}>0
$$

La inversión de las familias de la clase $b$ se define por la suma del valor financiado y el valor de la inversión autónoma. La inversión autónoma surge de la ecuación (21) y los préstamos por familia se determinan con la ecuación (22). El valor total de la inversión se obtiene mediante la ecuación (23):

$$
\begin{gathered}
i_{t}^{b} \equiv i^{b}\left(q_{t}\right)=\theta_{b} \cdot q_{t}, \quad \theta_{b}>0 \\
l_{t}^{*}=l\left(s_{t}, m_{t}\right), \quad l_{s}^{\prime}>0 \text { y } l_{m}^{\prime}>0 \\
i_{t}^{b} \equiv l_{t}^{*}+i_{t}^{b} \equiv l\left(s_{t}, m_{t}\right)+\theta_{b} \cdot q_{t}
\end{gathered}
$$

En estas ecuaciones, $m$ es la cantidad de fondos disponibles en la economía para préstamos a las familias y $s$ la cantidad de subsidios por familia. La inversión media por familia corresponde a la media ponderada de las inversiones de las familias de cada clase. Los 
elementos de ponderación corresponden a la influencia de cada clase en la sociedad, según el número de familias en cada clase dividido entre el total de familias. Al definir la influencia de cada clase como $\phi_{a}, \phi_{b}$ y $\phi_{c}$, de modo que $\phi_{a}+\phi_{b}+\phi_{c}=1$, se obtiene la ecuación (24).

$$
\begin{gathered}
i_{t} \equiv \phi_{a} \cdot\left(\theta_{a} \cdot q_{t}\right)+\phi_{b} \cdot\left(l_{t}^{*}+\theta_{b} \cdot q_{t}\right)+\phi_{c} \cdot\left(\theta_{c} \cdot q_{t}\right), \quad \mathrm{o} \\
i_{t} \equiv \phi_{b} \cdot l_{t}^{*}+\theta \cdot q_{t}
\end{gathered}
$$

donde $\phi_{a} \cdot \theta_{a}+\phi_{b} \cdot \theta_{b}+\phi_{c} \cdot \theta_{c}=\theta$. Por construcción, $\theta$ es un valor positivo. Al sustituir la ecuación (22) en la expresión (24), y el resultado de esa sustitución en la ecuación de acumulación de capital habitacional —expresión (18)_-, resulta:

$$
\dot{k}_{t}=\phi_{b} \cdot l\left(s_{t}, m_{t}\right)+\theta \cdot\left(q_{t}\right)-(n+\delta) \cdot k_{t}
$$

Las ecuaciones (17) y (25) forman el sistema de ecuaciones diferenciales que define el equilibrio dinámico en el mercado inmobiliario ${ }^{15}$. El equilibrio del sistema se encuentra en el estado estacionario de las variables $q$ y $k$. Las expresiones (26) y (27) describen las curvas de equilibrio del precio y de la cantidad de capital habitacional. Mientras que la curva descrita por la ecuación (26) tiene inclinación negativa, la curva descrita por la ecuación (27) tiene inclinación positiva. El equilibrio se define en la intersección de las dos curvas y los valores que equilibran el sistema se presentan en las expresiones (28) y (29).

$$
\begin{gathered}
\dot{q}_{t}=0 \Rightarrow q_{t}=\frac{f\left(w_{t}\right)-k_{t}}{\beta \cdot\left(r^{k}+\delta\right)} \\
\left.\frac{d q_{t}}{d k_{t}}\right|_{\dot{q}_{t}=0}=\frac{-1}{\beta \cdot\left(r^{k}+\delta\right)}<0
\end{gathered}
$$

${ }^{15} \mathrm{El}$ sistema posee estabilidad de punto de silla, pues el determinante jacobiano es negativo.

$$
|J|=\left|\begin{array}{cc}
r^{k}+\delta & 1 / \beta \\
\theta & -(n+\delta)
\end{array}\right|=-(n+\delta) \cdot\left(r^{k}+\delta\right)-\frac{\theta}{\beta}<0
$$

$$
\begin{gathered}
\dot{k}_{t}=0 \Rightarrow k_{t}=\frac{\phi_{b} \cdot l\left(s_{t}, m_{t}\right)+\theta \cdot\left(q_{t-1}\right)}{(n+\delta)} \\
\left.\frac{d q_{t}}{d k_{t}}\right|_{k_{t}=0}=\frac{n+\delta}{\theta}>0 \\
q^{*}=\frac{f\left(w_{t}\right) \cdot(n+\delta)-\phi_{b} \cdot l\left(s_{t}, m_{t}\right)+\theta}{\beta \cdot\left(r^{k}+\delta\right) \cdot(n+\delta)+\theta}
\end{gathered}
$$

$$
k^{*}=\frac{\beta \cdot\left(r^{k}+\delta\right) \cdot \phi_{b} \cdot l\left(s_{t}, m_{t}\right)+\theta \cdot\left[f\left(w_{t}\right)-\beta \cdot\left(r^{k}+\delta\right)\right]}{\beta \cdot\left(r^{k}+\delta\right) \cdot(n+\delta)+\theta}
$$

Por último, cabe evaluar los efectos de los cambios en las variables exógenas del sistema - la cantidad de subsidios por familia $\left(s_{t}\right)$, el valor de los fondos disponibles para préstamos por familia $\left(m_{t}\right)$, la riqueza media de las familias $\left(w_{t}\right)$ y la tasa de crecimiento del número de familias $\left(n_{t}\right)$ - en el equilibrio del mercado habitacional. Un aumento del monto de subsidio por familia disminuye el valor del inmueble y acrecienta la cantidad de capital. Esos efectos, descritos por las derivadas parciales presentadas a continuación, corresponden a un movimiento descendente de la curva $\dot{k}_{t}=0$ (véase el gráfico $\left.4(\mathrm{a})\right)^{16}$.

$$
\begin{gathered}
\frac{\partial q^{*}}{\partial s}=\frac{-\phi_{b} \cdot l_{s}^{\prime}}{\beta \cdot(n+\delta) \cdot\left(r^{k}+\delta\right)+\theta}<0 \mathrm{y} \\
\frac{\partial k^{*}}{\partial s}=\frac{\beta \cdot \phi_{b} \cdot l_{s}^{\prime} \cdot\left(r^{k}+\delta\right)}{\beta \cdot(n+\delta) \cdot\left(r^{k}+\delta\right)+\theta}>0
\end{gathered}
$$

De haber en la economía un incremento de los fondos disponibles para préstamos, el precio del inmueble debe disminuir y la cantidad de capital debe aumentar. Esto se debe a que la curva $\dot{k}_{t}=0$ también se desplaza hacia abajo (véase el gráfico 4(b)). Estos efectos se describen mediante las derivadas parciales:

\footnotetext{
16 En este modelo, la magnitud de los efectos del subsidio en el precio del inmueble y la cantidad de capital habitacional de equilibrio tienden a ser mayores en sociedades en que la clase media tiene una mayor influencia.
} 


$$
\begin{gathered}
\frac{\partial q^{*}}{\partial m}=\frac{-\phi_{b} \cdot l_{m}^{\prime}}{\beta \cdot(n+\delta) \cdot\left(r^{k}+\delta\right)+\theta}<0 \quad \mathrm{y} \\
\frac{\partial k^{*}}{\partial m}=\frac{\beta \cdot \phi_{b} \cdot l_{m}^{\prime} \cdot\left(r^{k}+\delta\right)}{\beta \cdot(n+\delta) \cdot\left(r^{k}+\delta\right)+\theta}>0
\end{gathered}
$$

La expansión de la riqueza de las familias aumenta el precio de mercado de los inmuebles tanto como la cantidad de capital habitacional. En este caso, hay un desplazamiento de la curva $\dot{q}_{t}=0$ hacia arriba (véase el gráfico 4(c)). Ese efecto se describe mediante las derivadas parciales de $q^{*}$ y $k^{*}$ con respecto a $w_{t}$. El incremento del ritmo de crecimiento de la población sube el precio de mercado de los inmuebles y disminuye la cantidad de capital habitacional por familia, como resultado del desplazamiento de la curva $\dot{k}_{t}=0$ hacia arriba.

$$
\begin{gathered}
\frac{\partial q^{*}}{\partial w}=\frac{(n+\delta) \cdot f^{\prime}\left(w_{t}\right)}{\beta \cdot(n+\delta) \cdot\left(r^{k}+\delta\right)+\theta}>0 \mathrm{y} \\
\frac{\partial k^{*}}{\partial w}=\frac{f^{\prime}\left(w_{t}\right) \cdot \theta}{\beta \cdot(n+\delta) \cdot\left(r^{k}+\delta\right)+\theta}>0
\end{gathered}
$$

$$
\begin{gathered}
\frac{\partial q^{*}}{\partial n}=\frac{k_{t}}{\beta \cdot(n+\delta) \cdot\left(r^{k}+\delta\right)+\theta}>0 \mathrm{y} \\
\frac{\partial k^{*}}{\partial n}=\frac{-\beta \cdot k_{t} \cdot\left(r^{k}+\delta\right)}{\beta \cdot(n+\delta) \cdot\left(r^{k}+\delta\right)+\theta}>0
\end{gathered}
$$

GRÁFICO 4

\section{Cambios en el equilibrio de estado estacionario}

(a)

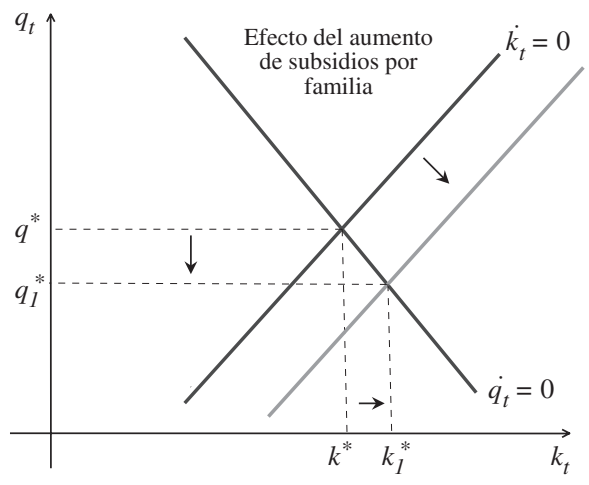

(c)

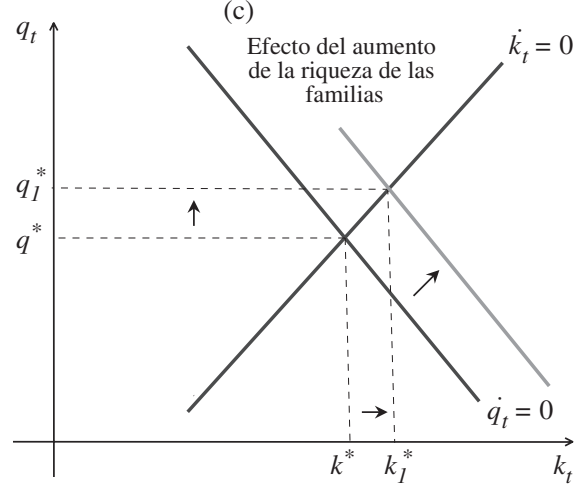

(b)

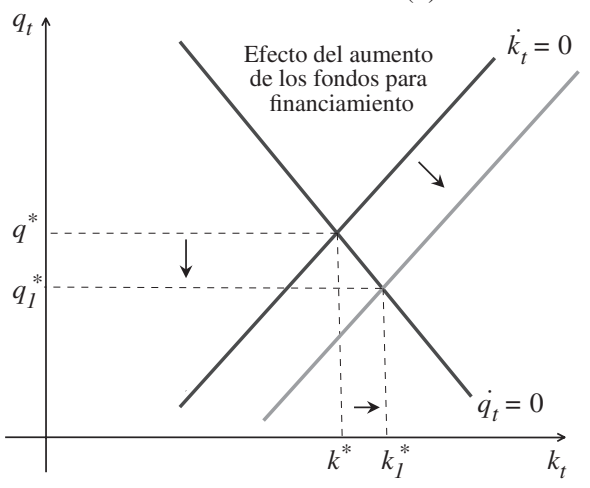

(d)

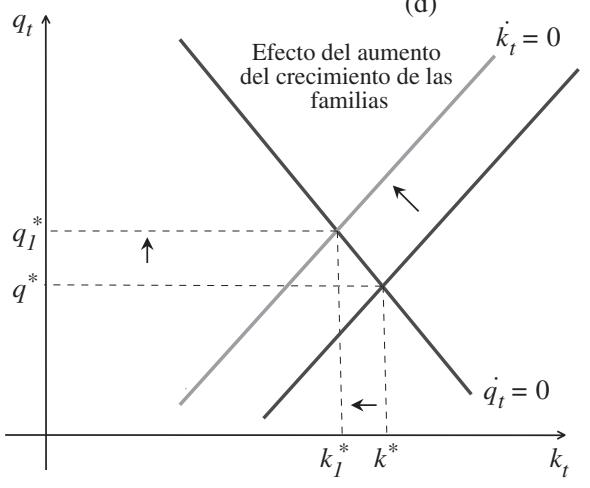

Fuente: elaboración propia sobre la base de Ana Lelia Magnabosco, "A política de subsídios habitacionais e sua influência na dinâmica de investimento imobiliário e no déficit de moradias do Brasil e do Chile", São Paulo, Pontificia Universidad Católica de São Paulo, 2011. 


\section{Subsidios y déficit habitacional}

Garcia y Rebelo (2002) propusieron una fórmula para relacionar la inversión en viviendas con el déficit habitacional. Para ello, partieron de la hipótesis de que hay un nivel arbitrario de ingresos $y_{c}$, debajo del cual no se satisfacen las necesidades habitacionales básicas. En otras palabras, por debajo de ese nivel la familia se encuentra en situación de déficit habitacional. En este artículo se adopta una visión parecida, en que la variable crítica es la cantidad de capital $\left(k_{c}\right)$.

Los resultados anteriores muestran que la riqueza familiar y la cantidad de capital habitacional están relacionados positivamente. De ese modo, para el nivel crítico $k_{c}$, hay un nivel crítico de riqueza $w_{c}$. Las familias con un nivel de riqueza muy bajo $\left(w_{l}\right)$ encuentran un equilibrio con una cantidad reducida de capital de estado estacionario; son las familias en situación de déficit. Aquellas que no se encuentran en condiciones deficitarias tienen una riqueza más elevada $\left(w_{h}\right)$. El precio de estado estacionario de los inmuebles (por $\mathrm{m}^{2}$ ) también es distinto para cada clase, lo que significa que el mercado de inmuebles está segmentado.

El déficit habitacional absoluto y relativo corresponde a:

$$
D_{i}=\int_{0}^{k_{c}} \pi_{i}(k) \cdot d k \quad \mathrm{y} \quad d_{i}=\frac{\int_{0}^{k_{c}} \pi_{i}(k) \cdot d k}{\int_{0}^{\infty} \pi_{i}(k) \cdot d k}
$$

donde $D_{i}$ es el déficit habitacional absoluto en una determinada región $i ; d_{i}$ es el déficit relativo; y $\pi_{i}(k)$ es la distribución de la cantidad de capital habitacional. La integral del numerador indica el número de familias con una reserva de capital hasta el nivel crítico y la del denominador indica el total de familias. Este razonamiento se ilustra en el gráfico 5.

GRÁFICO 5

\section{Distribución de las familias por cantidad de capital habitacional y déficit}

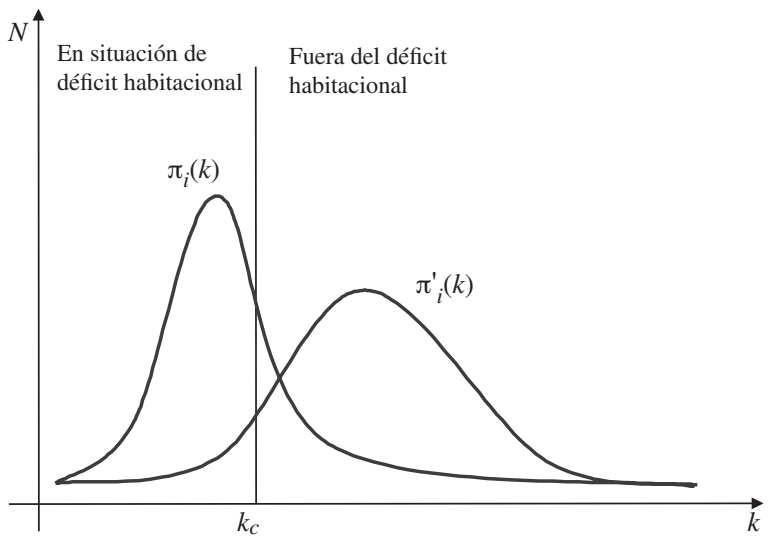

Fuente: elaboración propia sobre la base de Fernando Garcia y André Rebelo, "Déficit habitacional e desigualdade da renda familiar no Brasil", Revista de Economia Aplicada, vol. 6, No 3 , São Paulo.

Como se ilustra en el gráfico 5, la política de subsidios tiene un efecto de redistribución de la cantidad de capital de $\pi_{i}(k)$ a $\pi_{i}^{\prime}(k)$, que amplía el sector de la población que se encuentra sobre el nivel crítico de capital habitacional $\mathrm{y}$, por ende, reduce el número absoluto de familias en situación de déficit. En forma análoga, la expansión de los fondos para la inversión $(m)$ o de la riqueza de las familias $(w)$ disminuye el déficit habitacional absoluto y relativo, mientras que el crecimiento demográfico mayor incrementa el déficit habitacional.

$D_{i}=f\left(s_{i}, w_{i}, m_{i}, n_{i}\right), \quad f_{s}^{\prime}<0, f_{w}^{\prime}<0, f_{m}^{\prime}<0, f_{n}^{\prime}>0$

\section{IV}

\section{Efecto del subsidio en el crédito habitacional}

En esta sección se presenta un modelo econométrico con que se examinan los factores determinantes del crédito en Chile y el papel de los subsidios en ese proceso. El análisis empírico se basa en los datos de la Encuesta CASEN de 2009, realizada por el Ministerio de Desarrollo Social (ex MIDEPLAN). En el marco de la encuesta se entrevistaron 84.946 familias. Las variables monetarias se estandarizaron en dólares ajustados a la paridad del poder de compra de Chile, a precios de $2009^{17}$.

\footnotetext{
${ }^{17}$ El factor de conversión se tomó de los Indicadores del Desarrollo Mundial (en línea), del Banco Mundial.
} 
Se empleó un modelo de regresión logística con que se busca establecer los factores que determinan la probabilidad de obtención de crédito. El acceso al crédito (c) es una variable con distribución binaria, que indica si la familia adquirió el inmueble con crédito $(c=1)$ o no $(c=0)$. La función estimada se describe mediante la ecuación (32):

$$
\begin{aligned}
P(c=1 \mid X) & =G\left(\beta_{0}+\beta_{1} x_{1}+\ldots+\beta_{k} x_{k}\right) \\
& =G\left(\beta_{0}+X \beta\right)
\end{aligned}
$$

donde $G(z)$ es la función logística que asume valores entre cero (0) y uno (1) para todos los números $z$ reales, de modo que:

$$
G(z)=\frac{\exp (z)}{(1+\exp (z))}=\Lambda(z)^{18}
$$

${ }^{18}$ Esta es la función de distribución acumulativa de una variable aleatoria logística estándar.
El conjunto de variables que afectan a la probabilidad de que una familia tenga acceso al crédito $(X)$ incluye: el acceso de estas a los programas de subsidio; el ingreso mensual familiar; el número de personas que la integran; la edad del jefe de familia; la escolaridad de este; la ubicación del domicilio en zonas rurales o urbanas; las unidades regionales, y una variable ficticia de tiempo —llamada "régimen de financiamiento"- para distinguir las viviendas adquiridas después de 1976, año en que se realizaron las reformas del sistema de financiamiento habitacional chileno.

Los resultados de la regresión se detallan en el cuadro $3^{19}$. Los coeficientes de ingreso, acceso a subsidio, régimen de financiamiento y escolaridad del jefe de hogar son positivos y significativos, es decir que a medida que aumentan esas variables crece también la probabilidad de obtener crédito. El coeficiente ligado a la variable

${ }^{19}$ Debido a que la Encuesta CASEN se realiza por muestreo, cada observación tiene un peso atribuido por el proceso de selección de la muestra. En la regresión se tuvieron en cuenta las observaciones ponderadas por sus respectivos pesos muestrales.

\begin{tabular}{|c|c|c|c|c|c|c|}
\hline & \multirow{2}{*}{ Coeficiente } & \multirow{2}{*}{$\begin{array}{c}\text { Desviación } \\
\text { estándar }\end{array}$} & \multirow{2}{*}{$z$} & \multirow{2}{*}{$P>|z|$} & \multicolumn{2}{|c|}{ Intervalo de confianza (95\%) } \\
\hline & & & & & Inferior & Superior \\
\hline \multirow{3}{*}{$\begin{array}{l}\text { Ingreso mensual de la familia (ln) } \\
\text { Acceso al subsidio } \\
\text { Régimen de financiamiento }\end{array}$} & 0,3442 & 0,00144 & 239,86 & 0,0000 & 0,3414 & 0,3471 \\
\hline & 2,8449 & 0,00311 & 915,50 & 0,0000 & 2,8389 & 2,8510 \\
\hline & 0,1966 & 0,00365 & 53,91 & 0,0000 & 0,1894 & 0,2037 \\
\hline \multirow{3}{*}{$\begin{array}{l}\text { Número de personas } \\
\text { Edad del jefe de familia } \\
\text { Escolaridad del jefe }\end{array}$} & $-0,0538$ & 0,00077 & $-69,50$ & 0,0000 & $-0,0553$ & $-0,0522$ \\
\hline & $-0,0016$ & 0,00010 & $-15,74$ & 0,0000 & $-0,0018$ & $-0,0014$ \\
\hline & 0,0965 & 0,00038 & 254,18 & 0,0000 & 0,0958 & 0,0973 \\
\hline \multirow{2}{*}{ 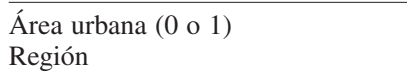 } & 1,1454 & 0,00495 & $-231,24$ & 0,0000 & $-1,1551$ & $-1,1357$ \\
\hline & & & & & & \\
\hline I Tarapacá & 0,6749 & 0,01654 & 40,80 & 0,0000 & 0,6424 & 0,7073 \\
\hline II Antofagasta & 0,2965 & 0,01640 & 18,08 & 0,0000 & 0,2643 & 0,3286 \\
\hline III Atacama & 0,9405 & 0,01819 & 51,71 & 0,0000 & 0,9049 & 0,9762 \\
\hline IV Coquimbo & 1,0538 & 0,01556 & 67,74 & 0,0000 & 1,0233 & 1,0843 \\
\hline V Valparaíso & 0,8854 & 0,01476 & 59,97 & 0,0000 & 0,8565 & 0,9144 \\
\hline VI Libertador O'Higgins & 0,9905 & 0,01546 & 64,08 & 0,0000 & 0,9602 & 1,0208 \\
\hline VII Maule & 0,5674 & 0,01523 & 37,25 & 0,0000 & 0,5376 & 0,5973 \\
\hline VIII Bío Bío & 0,7269 & 0,01470 & 49,44 & 0,0000 & 0,6981 & 0,7557 \\
\hline IX La Araucanía & 0,5393 & 0,01541 & 35,00 & 0,0000 & 0,5091 & 0,5695 \\
\hline $\mathrm{X} \quad$ Los Lagos & 0,7141 & 0,01511 & 47,27 & 0,0000 & 0,6845 & 0,7437 \\
\hline XI Aysén & 0,4735 & 0,02293 & 20,65 & 0,0000 & 0,4285 & 0,5184 \\
\hline XIII Región Metropolitana & 1,2471 & 0,01433 & 87,03 & 0,0000 & 1,2190 & 1,2752 \\
\hline Constante & $-6,4961$ & 0,01945 & $-216,18$ & 0,0000 & $-4,2434$ & $-4,1671$ \\
\hline
\end{tabular}

Chile: regresión logística de acceso al crédito

Fuente: elaboración propia sobre la base de la Encuesta de Caracterización Socioeconómica Nacional (CASEN) de 2009.

Nota: número de observaciones ponderadas $=3.553 .491$.

Grado de adecuación: $-2 \log$ de máxima verosimilitud $=3.340 .059$.

Grado de adecuación (pseudo $\mathrm{R}^{2}$ ) $=32,04 \%$. 
subsidio es de alrededor de tres. Eso indica que si la familia tiene acceso al subsidio, sus probabilidades de obtener crédito se incrementan en forma considerable. La variable régimen de financiamiento presentó un coeficiente positivo y significativo: después de 1976, las probabilidades de obtener crédito para la compra de la casa propia aumentan casi 20 puntos porcentuales con respecto al período anterior. Ese resultado refleja el efecto de las políticas impulsadas en ese período, que recuperaron las condiciones del crédito inmobiliario en Chile.

Con el modelo empírico descrito se corrobora la idea de que el acceso al subsidio afecta positivamente a la probabilidad de acceso al crédito. De ese modo, el subsidio complementa el ingreso de las familias pobres y reduce el riesgo de crédito de los bancos, permitiendo la expansión de la demanda y de la oferta de crédito. Sin embargo, una limitación importante de ese modelo es la ausencia de otras variables de control para la oferta de crédito en el mercado inmobiliario chileno. La muestra de la Encuesta CASEN analizada contiene viviendas adquiridas entre 1930 y 2009, o sea, compradas con y sin crédito en condiciones macroeconómicas y de regímenes de crédito muy distintas (véase la sección II).

Tal como se señaló en el modelo teórico, las condiciones macroeconómicas afectan a la oferta de fondos para el crédito inmobiliario y el valor de la entrada (relacionado con el ahorro previo) influye en la relación entre el valor de la hipoteca y el valor del préstamo, con repercusiones en el rendimiento de los bancos y la disposición a prestar. Debido a la reestructuración del sistema de crédito, la reforma del sistema de pensiones y la continua bancarización que tuvieron lugar en el período de referencia, la oferta de fondos en la economía chilena y el ahorro previo de las familias crecieron en forma considerable en esos años. También aumentó la proporción de familias que recurrieron al crédito para la adquisición de viviendas. En el gráfico 6 se observa claramente la tendencia creciente de esa proporción y se distinguen tres niveles históricos, que pueden vincularse a los regímenes de crédito descritos en la sección II de este artículo: hasta 1959, entre 1959 y 1976 y después de 1976.

En este marco, es válido preguntarse si la omisión de esos factores incide de manera decisiva en la estimación de la influencia del acceso al subsidio en el acceso al crédito. Al no haber modo de distinguir las condiciones de oferta de crédito entre los individuos de la muestra, se presupone que esas condiciones variaron muy poco en el tiempo. Una forma de captar la influencia de esas condiciones en la probabilidad de acceso es introducir en la regresión logística variables ficticias que indican

GRÁFICO 6

Chile: proporción de las viviendas adquiridas con crédito, 1949-2009

(En porcentajes)

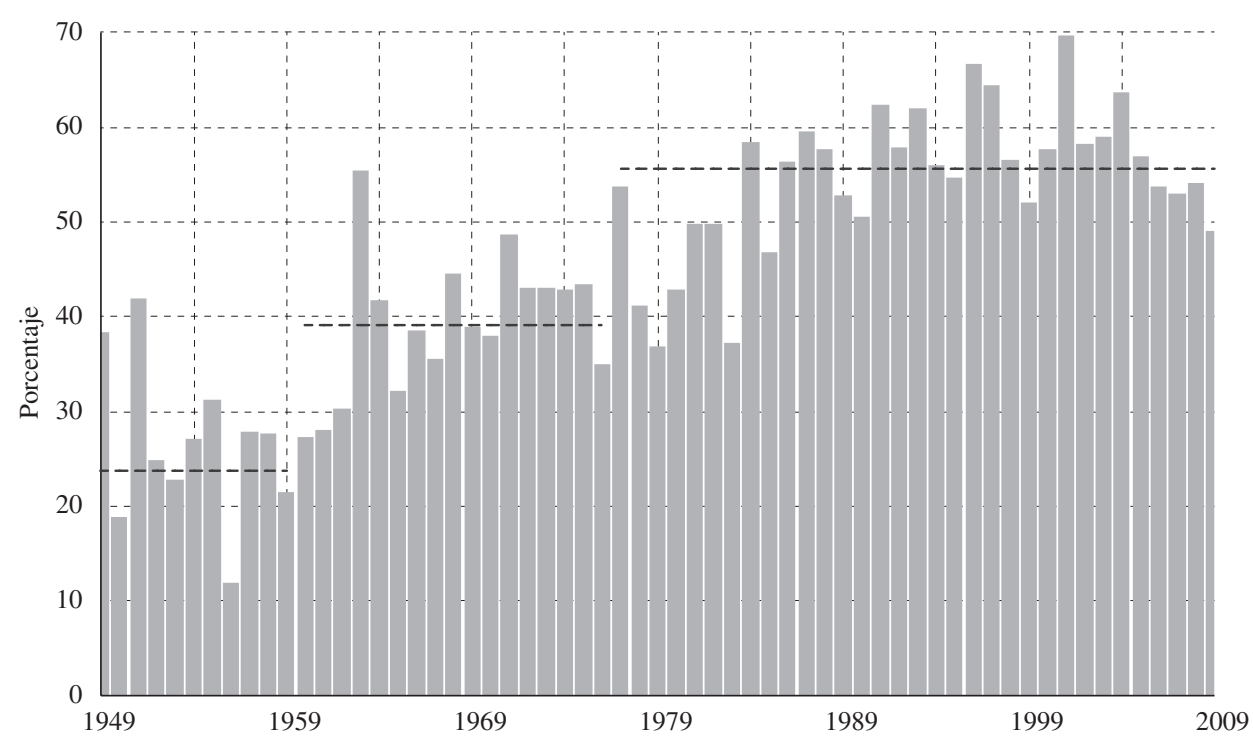

Fuente: elaboración propia sobre la base de la Encuesta de Caracterización Socioeconómica Nacional (CASEN) de 2009. 
el año de adquisición de la vivienda. El conjunto de variables ficticias pasa a informar las condiciones de oferta de crédito, equilibrando el conjunto de variables explicativas del modelo ${ }^{20}$. Los nuevos cálculos se presentan en el cuadro $4^{21}$.

\footnotetext{
${ }^{20}$ En este razonamiento está implícita la idea de que las condiciones macroeconómicas y el volumen de ahorro previo agregado de las familias en un determinado año afectan, de igual manera e intensidad, a la probabilidad de obtención de crédito de todas las familias que adquirieron sus viviendas ese año.

${ }^{21}$ El conjunto de variables ficticias que expresan el año de adquisición es significativo, según indica la prueba de máxima verosimilitud (LR). El valor calculado de la estadística LR es 87.600 , muy superior al valor crítico para cualquier nivel convencional de significancia. Por lo tanto, se rechaza la hipótesis nula de la prueba de que los coeficientes vinculados a las variables ficticias de año de adquisición de la vivienda no son significativos. Los valores de los coeficientes estimados captan la tendencia descrita en el gráfico 6 de incremento de la probabilidad de obtención de crédito.
}

Los resultados del cuadro 4 refuerzan los detallados en el cuadro 3, en la medida en que el coeficiente que relaciona el acceso al subsidio con el acceso al crédito tiene el mismo signo e igual magnitud. Lo mismo puede decirse con respecto a los coeficientes relacionados con las demás variables explicativas, con excepción del que relaciona la edad del jefe de familia con el acceso al crédito. Ese coeficiente cambia de signo, de negativo a positivo. Según el nuevo cálculo, a mayor edad del jefe de familia mayor probabilidad de obtener crédito, hecho que tiene más sentido económico. La corrección del coeficiente se debe a que existe una correlación positiva natural entre el año de adquisición de la vivienda y la edad del jefe de familia, que - cuando no se tiene en cuenta - sesga el coeficiente de esa variable. En consecuencia, las condiciones macroeconómicas e institucionales que afectan a la oferta de crédito no solo ayudan a explicar la probabilidad de obtención de crédito, sino que contribuyen a corregir los cálculos del modelo.

Chile: regresión logística de acceso al crédito, con variables ficticias de año de adquisición

\begin{tabular}{|c|c|c|c|c|c|c|}
\hline & \multirow{2}{*}{ Coeficiente } & \multirow{2}{*}{$\begin{array}{l}\text { Desviación } \\
\text { estándar }\end{array}$} & \multirow{2}{*}{$z$} & \multirow{2}{*}{$P>|z|$} & \multicolumn{2}{|c|}{ Intervalo de confianza (95\%) } \\
\hline & & & & & Inferior & Superior \\
\hline Ingreso mensual de la familia (ln) & 0,3156 & 0,00143 & 221,20 & 0,0000 & 0,3128 & 0,3184 \\
\hline Acceso al subsidio & 2,8449 & 0,00311 & 915,50 & 0,0000 & 2,8389 & 2,8510 \\
\hline Número de personas & $-0,0352$ & 0,00077 & $-45,52$ & 0,0000 & $-0,0367$ & $-0,0337$ \\
\hline Edad del jefe de familia & 0,0016 & 0,00011 & 15,10 & 0,0000 & 0,0014 & 0,0018 \\
\hline Escolaridad del jefe & 0,0968 & 0,00038 & 256,51 & 0,0000 & 0,0960 & 0,0975 \\
\hline Área urbana $\left(\begin{array}{lll}0 & \text { o } & 1\end{array}\right)$ & 1,1993 & 0,00496 & 241,57 & 0,0000 & 1,1895 & 1,2090 \\
\hline \multicolumn{7}{|l|}{ Región } \\
\hline I Tarapacá & 0,7667 & 0,01663 & 46,11 & 0,0000 & 0,7341 & 0,7992 \\
\hline II Antofagasta & 0,4507 & 0,01652 & 27,28 & 0,0000 & 0,4183 & 0,4831 \\
\hline III Atacama & 1,0398 & 0,01817 & 57,22 & 0,0000 & 1,0042 & 1,0755 \\
\hline IV Coquimbo & 1,1121 & 0,01576 & 70,54 & 0,0000 & 1,0812 & 1,1430 \\
\hline V Valparaíso & 0,9690 & 0,01498 & 64,67 & 0,0000 & 0,9396 & 0,9984 \\
\hline VI Libertador O'Higgins & 1,1386 & 0,01564 & 72,78 & 0,0000 & 1,1080 & 1,1693 \\
\hline VII Maule & 0,6774 & 0,01544 & 43,88 & 0,0000 & 0,6471 & 0,7077 \\
\hline VIII Bío Bío & 0,8243 & 0,01491 & 55,28 & 0,0000 & 0,7951 & 0,8535 \\
\hline IX La Araucanía & 0,6300 & 0,01559 & 40,41 & 0,0000 & 0,5994 & 0,6605 \\
\hline $\mathrm{X} \quad$ Los Lagos & 0,8000 & 0,01530 & 52,29 & 0,0000 & 0,7700 & 0,8300 \\
\hline XI Aysén & 0,6129 & 0,02269 & 27,01 & 0,0000 & 0,5684 & 0,6574 \\
\hline XIII Región Metropolitana & 1,3805 & 0,01455 & 94,85 & 0,0000 & 1,3520 & 1,4090 \\
\hline Constante & $-5,7599$ & 0,26354 & $-21,86$ & 0,0000 & $-6,2764$ & $-5,2434$ \\
\hline
\end{tabular}

Fuente: elaboración propia sobre la base de la Encuesta de Caracterización Socioeconómica Nacional (CASEN) de 2009.

Nota: número de observaciones ponderadas $=3.553 .491$.

Grado de adecuación: $-2 \log$ de máxima verosimilitud = 3.427.659,4.

Grado de adecuación (pseudo $\mathrm{R}^{2}$ ) $=33,43 \%$. 


\section{Subsidios, crédito y déficit habitacional en Chile}

En esta sección se analiza el déficit habitacional en Chile. Después de definir la metodología de medición del déficit empleada en el artículo y analizar su evolución reciente, se investigan los factores determinantes del déficit habitacional, destacando el papel de los subsidios y del crédito inmobiliario.

\section{Déficit habitacional}

Existen varias metodologías alternativas que se emplean para medir el déficit habitacional chileno. Simian (2010) cita tres metodologías principales: la del Ministerio de Vivienda y Urbanismo (MINVU), la de la Cámara Chilena de la Construcción y la del centro de estudios Libertad y Desarrollo. Estas difieren en términos de conceptos y los cálculos numéricos varían bastante entre una y otra.

Arriagada (2005) analiza los métodos empleados para medir el déficit habitacional en los países de América Latina y señala dos conceptos presentes en casi todas las metodologías: las viviendas de material precario y los hogares allegados, con más de una familia compartiendo la vivienda, se consideran en situación de déficit habitacional, es decir, suponen la necesidad de reposición y ampliación inmediata de la cantidad de viviendas.

En este artículo se emplea una metodología basada en Szalachman (2000) para estimar el déficit habitacional en Chile. Esa metodología es menos restrictiva y reúne los elementos comunes a la mayor parte de los estudios en este campo. Además de permitir la comparación con otros países, en esta metodología no se emplean criterios de ingresos para seleccionar a las familias en déficit, lo que permite utilizar el ingreso en los modelos explicativos del déficit habitacional. En el recuadro 1 se presentan los conceptos empleados para la estimación del déficit habitacional en Chile, que se analiza en las dimensiones "precariedad de las viviendas" y "cohabitación"22.

En el cuadro 5 se presenta la evolución del número de familias en las dos dimensiones del déficit habitacional, entre 1996 y 2009. En primer lugar, se observa una marcada reducción del contingente de familias que vivían en viviendas precarias, el que pasó de 148.000 en 1996 a 67.000 en 2009. Eso equivale a una disminución del $5,9 \%$ al año entre 1996 y 2009. Esa trayectoria parece estar relacionada con el aumento sistemático de los subsidios habitacionales y del crédito en las décadas de 1990 y 2000.

\footnotetext{
${ }^{22}$ En el concepto de precariedad de las viviendas empleado en este artículo, no se tuvieron en cuenta las condiciones externas de la vivienda, como la existencia de servicios de saneamiento, acceso al agua, recolección de basura e infraestructura urbana. Esas características no se incorporaron al análisis porque la inversión para la construcción de esas redes y servicios no pasa por la decisión individual ni por el mercado de crédito inmobiliario. Se trata de servicios públicos cuya instalación y operación están sujetos a otro tipo de restricciones de crédito y a otros procesos de decisión. Esos temas, de la mayor importancia para el contexto habitacional y urbano, requieren un tratamiento distinto del empleado en este artículo.
}

RECUADRO 1

Conceptos utilizados para la estimación del déficit habitacional

\begin{tabular}{|c|c|c|}
\hline Componentes & \multicolumn{2}{|l|}{ Especificación } \\
\hline \multirow[t]{4}{*}{ Precariedad } & \multicolumn{2}{|c|}{ Familias que viven en viviendas incluidas en por lo menos una de las tres categorías siguientes: } \\
\hline & i) Viviendas improvisadas & $\begin{array}{l}\text { Locales e inmuebles sin fines residenciales que sirven como vivienda } \\
\text { alternativa (inmuebles comerciales, debajo de puentes y viaductos, } \\
\text { carcasas de vehículos abandonados, barcos, cavernas, entre otros) }\end{array}$ \\
\hline & ii) Domicilios rústicos & Aquellos que no tienen paredes de albañilería o madera \\
\hline & iii) Habitaciones alquiladas o cedidas & Corresponden a la vivienda en habitaciones alquiladas o cedidas \\
\hline
\end{tabular}

Fuente: elaboración propia sobre la base de Camilo Arriagada, "El déficit habitacional en Brasil y México y sus dos megaciudades globales: Estudio con los censos de 1990 y 2000", serie Población y Desarrollo, № 62 (LC/L.2433-P), Santiago de Chile, Comisión Económica para América Latina y el Caribe (cepal), 2005. Publicación de las Naciones Unidas, N de venta: S.05.II.G.179. 
Chile: número de familias en situación de déficit habitacional, 1996 a 2009

\begin{tabular}{|c|c|c|c|c|c|}
\hline \multirow{2}{*}{ Año } & \multirow{2}{*}{ Precariedad } & \multirow{2}{*}{ Cohabitación } & \multirow{2}{*}{ Total de familias } & \multicolumn{2}{|c|}{ Déficit relativo (en porcentajes) } \\
\hline & & & & Precariedad & Cohabitación \\
\hline 1996 & 147915 & 711172 & 4334620 & 3,41 & 16,41 \\
\hline 1998 & 164615 & 745667 & 4522690 & 3,64 & 16,49 \\
\hline 2000 & 166608 & 822220 & 4723832 & 3,53 & 17,41 \\
\hline 2003 & 116835 & 898422 & 5028826 & 2,32 & 17,87 \\
\hline 2006 & 78717 & 975828 & 5312894 & 1,48 & 18,37 \\
\hline 2009 & 66859 & 941377 & 5626867 & 1,19 & 16,73 \\
\hline Variación (en porcentajes) $)^{\mathrm{a}}$ & $-5,90$ & 2,20 & 2,00 & $-2,22$ & 0,32 \\
\hline
\end{tabular}

Fuente: elaboración propia sobre la base de la Encuesta de Caracterización Socioeconómica Nacional (CASEN) (varios años).

a En el caso del déficit relativo, se trata de la diferencia en puntos porcentuales entre 1996 y 2009.

En la trayectoria de 13 años, el número de familias que cohabitaban creció un 2,2\% al año. Además de registrar una tendencia distinta de la precariedad, este sector representa entre el $16 \%$ y el $19 \%$ de las familias chilenas. Eso indica que, a pesar de la expansión de los subsidios y el crédito para las familias a lo largo de esos años, el aumento de la cohabitación se mantuvo hasta el año 2006.

De acuerdo con la ministra Patricia Poblete Bennett ${ }^{23}$, muchas familias en Chile viven con familiares ya que carecen de las condiciones para mantener un domicilio propio. Esas familias no deberían siquiera considerarse en el déficit habitacional, pues la construcción de una vivienda no resolvería el problema. De hecho, los datos recogidos por la Encuesta CASEN de 2009 confirman ese fenómeno. De las más de 941.000 familias que vivían en la residencia de otras familias, 577.000 (equivalentes al 61,3\%) alegaron razones económicas para la cohabitación. Por otra parte, cerca del $20 \%$ de las familias en esa situación declararon motivos de tradición familiar o preferencia por la vivienda compartida. En la misma encuesta se agrega que una parte minoritaria $(42,2 \%)$ de las familias convivientes tenía planes de constituir un domicilio propio en los próximos años ${ }^{24}$.

\section{Factores determinantes del déficit}

En el análisis empírico desarrollado en esta sección también se utiliza la base de datos de la Encuesta CASEN

\footnotetext{
${ }^{23}$ Las opiniones de la Sra. Patricia Poblete Bennett, ministra del Ministerio de Vivienda y Urbanismo de Chile en el gobierno de Michele Bachelet, se tomaron de Magnabosco (2011) - Anexo 2.5. ${ }^{24}$ En la metodología de déficit habitacional empleada en el Brasil, que fue desarrollada por la Fundación João Pinheiro, se excluye del déficit a las familias en cohabitación que no tienen intención de constituir una vivienda propia.
}

de 2009. Al igual que para el análisis de la relación entre crédito y subsidio, la variable ingresos de la familia se estandarizó en dólares ajustados a la paridad del poder de compra de Chile, a precios de 2009.

Los modelos de regresión logística empleados para identificar los factores determinantes del déficit tienen como variables dependientes la pertenencia al grupo en situación de precariedad (0 no; 1 sí) y la pertenencia al grupo en situación de cohabitación (0 no; 1 sí). La especificación de las ecuaciones estimadas es la de la expresión (32) de la sección anterior y las distribuciones están condicionadas a las variables que indican si las familias tuvieron acceso a los programas de subsidio y de crédito y, también, al ingreso mensual familiar. En el conjunto de variables de control se incluyen el número de personas por familia, la edad del jefe de familia, la escolaridad del jefe de familia, la ubicación del domicilio en zonas rurales o urbanas y las unidades regionales. En los cuadros 6 y 7 se detallan los resultados de las regresiones logísticas de determinación de la probabilidad de padecer el déficit por precariedad y por cohabitación.

Los resultados del cuadro 6 son bastante significativos. Los coeficientes de ingresos, acceso al crédito y acceso al subsidio son negativos. Conforme aumenta el ingreso familiar, se reduce la probabilidad de padecer el déficit por precariedad. El acceso al crédito y al subsidio también disminuyen considerablemente la probabilidad de que una familia viva en una vivienda precaria. El número de personas en la familia, la edad y la escolaridad de los jefes de familia también afectan de forma negativa a esa probabilidad. Las variables espaciales indican que ese déficit es menos frecuente en las áreas urbanas y en las regiones al sur del país. Las regiones donde las familias tienen mayores probabilidades de vivir en una vivienda precaria son las de Antofagasta y Atacama. 
Chile: regresión logística de pertenencia al grupo en situación de precariedad

\begin{tabular}{|c|c|c|c|c|c|c|}
\hline & \multirow{2}{*}{ Coeficiente } & \multirow{2}{*}{$\begin{array}{c}\text { Desviación } \\
\text { estándar }\end{array}$} & \multirow{2}{*}{$z$} & \multirow{2}{*}{$P>|z|$} & \multicolumn{2}{|c|}{ Intervalo de confianza (95\%) } \\
\hline & & & & & Inferior & Superior \\
\hline Acceso al crédito & $-2,2771$ & 0,03476 & $-65,52$ & 0,0000 & $-2,3453$ & $-2,2090$ \\
\hline Acceso al subsidio & $-1,5298$ & 0,02546 & $-60,09$ & 0,0000 & $-1,5797$ & $-1,4799$ \\
\hline Número de personas & $-0,4027$ & 0,00271 & $-148,68$ & 0,0000 & $-0,4080$ & $-0,3973$ \\
\hline Escolaridad del jefe & $-0,1146$ & 0,00111 & $-102,94$ & 0,0000 & $-0,1168$ & $-0,1124$ \\
\hline Área urbana ( 0 o 1$)$ & $-0,3799$ & 0,01095 & 34,68 & 0,0000 & 0,3584 & 0,4013 \\
\hline \multicolumn{7}{|l|}{ Región } \\
\hline I Tarapacá & 1,7048 & 0,30313 & 12,41 & 0,0000 & 3,1692 & 4,3574 \\
\hline II Antofagasta & 3,0099 & 0,30207 & 16,78 & 0,0000 & 4,4764 & 5,6605 \\
\hline III Atacama & 2,8765 & 0,30242 & 16,32 & 0,0000 & 4,3423 & 5,5278 \\
\hline IV Coquimbo & 2,1969 & 0,30213 & 14,08 & 0,0000 & 3,6633 & 4,8476 \\
\hline VI Libertador O'Higgins & 2,1299 & 0,30200 & 13,87 & 0,0000 & 3,5965 & 4,7804 \\
\hline VII Maule & 1,3610 & 0,30222 & 11,31 & 0,0000 & 2,8272 & 4,0119 \\
\hline VIII Bío Bío & 1,7982 & 0,30185 & 12,78 & 0,0000 & 3,2651 & 4,4483 \\
\hline IX La Araucanía & 1,4872 & 0,30218 & 11,73 & 0,0000 & 2,9534 & 4,1380 \\
\hline $\mathrm{X} \quad$ Los Lagos & 1,5587 & 0,30203 & 11,98 & 0,0000 & 3,0253 & 4,2092 \\
\hline XI Aysén & $-2,0585$ & 0,32746 & 6,29 & 0,0000 & 1,4167 & 2,7003 \\
\hline XIII Región Metropolitana & 2,2047 & 0,30170 & 14,13 & 0,0000 & 3,6719 & 4,8546 \\
\hline Constante & 0,8941 & 0,30328 & $-6,34$ & 0,0000 & $-2,5185$ & $-1,3297$ \\
\hline
\end{tabular}

Fuente: elaboración propia sobre la base de la Encuesta de Caracterización Socioeconómica Nacional (CASEN) de 2009.

Nota: número de observaciones ponderadas $=5.431 .713$.

Grado de adecuación: $-2 \log$ de máxima verosimilitud = 593.702 .

Grado de adecuación (pseudo $\mathrm{R}^{2}$ ) $=15,89 \%$.

CUADRO 7

Chile: regresión logística de pertenencia al grupo en condiciones de cohabitación

\begin{tabular}{|c|c|c|c|c|c|c|}
\hline & \multirow{2}{*}{ Coeficiente } & \multirow{2}{*}{$\begin{array}{c}\text { Desviación } \\
\text { estándar }\end{array}$} & \multirow{2}{*}{$z$} & \multirow{2}{*}{$P>|z|$} & \multicolumn{2}{|c|}{ Intervalo de confianza (95\%) } \\
\hline & & & & & Inferior & Superior \\
\hline Ingreso mensual de la familia (ln) & $-0,9295$ & 0,00180 & $-517,23$ & 0,0000 & $-0,9330$ & $-0,9259$ \\
\hline Acceso al crédito & 0,0751 & 0,00480 & 15,66 & 0,0000 & 0,0657 & 0,0845 \\
\hline Acceso al subsidio & $-0,0464$ & 0,00480 & $-9,67$ & 0,0000 & $-0,0558$ & $-0,0370$ \\
\hline Número de personas & 0,6503 & 0,00096 & 680,00 & 0,0000 & 0,6484 & 0,6522 \\
\hline Edad del jefe de familia & $-0,0732$ & 0,00014 & $-527,73$ & 0,0000 & $-0,0735$ & $-0,0730$ \\
\hline Escolaridad del jefe & 0,1121 & 0,00053 & 212,57 & 0,0000 & 0,1111 & 0,1131 \\
\hline Área urbana (l 0 o 1$)$ & 0,0954 & 0,00545 & $-17,53$ & 0,0000 & $-0,1061$ & $-0,0848$ \\
\hline Región & & & & & & \\
\hline I Tarapacá & 0,5279 & 0,02090 & 2,14 & 0,0320 & 0,0039 & 0,0858 \\
\hline II Antofagasta & 0,7758 & 0,02052 & 14,26 & 0,0000 & 0,2525 & 0,3329 \\
\hline III Atacama & 0,2476 & 0,02291 & $-10,28$ & 0,0000 & $-0,2804$ & $-0,1906$ \\
\hline IV Coquimbo & 0,4963 & 0,02053 & 0,64 & 0,5190 & $-0,0270$ & 0,0535 \\
\hline V Valparaíso & 0,5857 & 0,01951 & 5,26 & 0,0000 & 0,0644 & 0,1408 \\
\hline VI Libertador O Higgins & 0,8367 & 0,02011 & 17,59 & 0,0000 & 0,3142 & 0,3930 \\
\hline VII Maule & 0,4005 & 0,02019 & $-4,09$ & 0,0000 & $-0,1222$ & $-0,0430$ \\
\hline VIII Bío Bío & 0,4868 & 0,01945 & 0,19 & 0,8490 & $-0,0344$ & 0,0418 \\
\hline IX La Araucanía & $-0,0545$ & 0,02052 & $-26,20$ & 0,0000 & $-0,5778$ & $-0,4974$ \\
\hline $\mathrm{X} \quad$ Los Lagos & 0,4856 & 0,01988 & 0,13 & 0,9000 & $-0,0365$ & 0,0415 \\
\hline XI Aisén & 0,4831 & 0,03284 & $-14,71$ & 0,0000 & $-0,5474$ & $-0,4187$ \\
\hline XIII Región Metropolitana & 0,8278 & 0,01905 & 18,10 & 0,0000 & 0,3074 & 0,3821 \\
\hline Constante & 2,7273 & 0,02384 & 142,65 & 0,0000 & 3,3545 & 3,4480 \\
\hline
\end{tabular}

Fuente: elaboración propia sobre la base de la Encuesta de Caracterización Socioeconómica Nacional (CASEN) de 2009.

Nota: número de observaciones ponderadas $=5.431 .713$.

Grado de adecuación: $-2 \log$ de máxima verosimilitud = 2.675.684.

Grado de adecuación (pseudo $\mathrm{R}^{2}$ ) $=40,85 \%$. 
Los resultados del cuadro 7 , referidos a la probabilidad de pertenencia al grupo en condiciones de cohabitación, son aún más significativos. Los coeficientes de ingresos y acceso al subsidio son negativos, lo que indica que el acceso al subsidio y el mayor ingreso familiar reducen la probabilidad de pertenecer al grupo en condiciones de cohabitación. El acceso al crédito, por el contrario, aumenta la probabilidad de que una familia comparta la vivienda con otras familias. El número de personas en la familia y la escolaridad de los jefes de familia afectan positivamente a esa probabilidad, indicando que la cohabitación es más frecuente en familias más numerosas y cuyo jefe tiene una escolaridad más elevada. La edad del jefe de familia tiene coeficiente negativo, señalando que la cohabitación es más frecuente en familias encabezadas por jóvenes. Las variables espaciales indican que ese déficit es más frecuente en las áreas urbanas y en las regiones más pobladas del país: Región Metropolitana de Santiago y Libertador Bdo. O’Higgins.

Se debe prestar particular atención al coeficiente positivo que relaciona el acceso al crédito con la probabilidad de cohabitación, pues esas dos variables pueden estar ligadas a otros aspectos del comportamiento de las familias chilenas que no están presentes en la visión teórica del mercado inmobiliario desarrollada en este artículo. Además de la cohabitación por razones de preferencia y tradición familiar, se debe destacar la estrategia económica de las familias de compartir bienes duraderos de consumo y de incrementar la riqueza del grupo familiar.

La estrategia de compartir bienes duraderos de consumo se infiere de los datos de la Encuesta CASEN. La propiedad de ese tipo de bienes es mucho más frecuente en las familias principales que en las secundarias. Por ejemplo, en 2009, mientras que el $91,6 \%$ de las familias principales tenían un refrigerador, esa frecuencia disminuía al 6,9\% en el caso de las familias secundarias. Esto denota la dependencia del refrigerador de la familia principal. La estrategia de incremento de la riqueza del grupo familiar se refleja en la cantidad de familias secundarias que tienen un inmueble propio o están pagando un crédito hipotecario (287.500, que corresponde al 30,5\% de las familias en cohabitación). Las viviendas de esas familias están —en su gran mayoría — alquiladas, lo que aumenta el flujo de ingresos del grupo familiar.

\section{VI}

\section{Consideraciones finales}

En este artículo se abordó la política habitacional de Chile, donde se implementaron profundas reformas del sistema de financiamiento habitacional a mediados de la década de 1970, resaltando la estrategia de conjugar el crédito al subsidio en el financiamiento inmobiliario. Esa política produjo resultados positivos en el combate al déficit, sobre todo en la reducción de la cantidad de viviendas precarias, y se volvió una referencia en ese ámbito para América Latina. Más allá de los programas de gobierno, la política habitacional chilena se consagró como una política de Estado, que se mantuvo durante varias administraciones con tendencias ideológicas distintas.

Tomando como base el sistema de financiamiento en Chile, en que la compra del inmueble se realiza mediante recursos de ahorro previo, crédito y subsidio, se desarrolló un modelo teórico para analizar la influencia de la política de subsidios habitacionales en el mercado de crédito y en el mercado inmobiliario. La concesión de subsidios para la compra de la vivienda aumenta el rendimiento de los préstamos bancarios y amplía la oferta de crédito. El subsidio también incrementa la demanda de préstamos. El aumento de los subsidios y la expansión de la oferta de crédito cambian el equilibrio del mercado inmobiliario, lo que redunda en un acrecentamiento del capital habitacional por familia y una disminución de los precios de los inmuebles, con repercusiones en el déficit habitacional.

Esas relaciones teóricas orientaron los análisis econométricos desarrollados en las secciones siguientes. En primer lugar, cabe mencionar que los resultados econométricos obtenidos con respecto a Chile corroboran las propuestas teóricas formuladas en el artículo. Los dos nuevos resultados teóricos más importantes no fueron refutados por los datos: i) el acceso al subsidio influye en forma decisiva en la concesión de crédito, aumentando directamente la probabilidad de que una familia acceda a este; y ii) el incremento del volumen del subsidio reduce el número de familias con capital habitacional inferior al nivel crítico, es decir, en situación de déficit habitacional. 
Los resultados econométricos también ayudan a interpretar la evolución del déficit habitacional en Chile de 1996 a 2009. Año a año se concedieron nuevos subsidios y el porcentaje de las familias asistidas por la política se elevó. Mientras que en 1996 el 20,9\% de las familias chilenas había recibido algún tipo de subsidio habitacional, en 2009 ese porcentaje alcanzó al 28,2\%. El crédito también fluyó a buen ritmo: el porcentaje de familias con acceso al crédito inmobiliario pasó del 22,3\% en 1996 al 31,0\% en 2009. El ingreso medio de las familias chilenas creció de 1.600 dólares, ajustados a la paridad del poder de compra, a 2.100 dólares, que equivalen a un crecimiento del $27 \%$ en el período examinado.

Esa evolución del crédito y del subsidio, así como el crecimiento del ingreso de las familias, condujo a la reducción gradual del déficit por precariedad, de acuerdo con lo esperado por el modelo teórico y previsto por el análisis econométrico. El patrón de la evolución de esas variables también explica la persistencia, en términos relativos, de las familias en condiciones de cohabitación. En el período de referencia creció el porcentaje de familias con acceso al crédito y Chile avanzó en materia de urbanización ${ }^{25}$, hechos que acabaron por abultar la frecuencia de la cohabitación. Aparentemente, el aumento de la cohabitación no fue aun mayor debido al incremento del acceso al subsidio, del ingreso medio familiar y de la edad media de los jefes de familia ${ }^{26}$.

Los resultados indican que la política chilena de subsidios habitacionales tiene efectos considerables en el déficit, disminuyendo la precariedad y recomponiendo sus dimensiones, con un aumento relativo de la cohabitación. Estas pruebas amplían el conocimiento de los efectos de la política habitacional, de utilidad no solo para el análisis del mercado inmobiliario chileno, sino también para la investigación en otros países latinoamericanos, como México y el Brasil, donde se adoptaron políticas similares a la chilena en la década de 2000.

\footnotetext{
${ }^{25}$ En términos absolutos, entre 1996 y 2009, surgieron 1 millón 167 mil nuevas familias en las áreas urbanas y apenas 83.000 nuevas familias en las áreas rurales chilenas. El porcentaje de familias que vivían en zonas urbanas pasó del 85,7\% al 87,4\% en el mismo período. ${ }^{26} \mathrm{La}$ edad media de los jefes de familia pasó de 45,6 años en 1996 a 49,3 años en 2009.
}

\section{Bibliografía}

Arriagada, Camilo (2005), "El déficit habitacional en Brasil y México y sus dos megaciudades globales: Estudio con los censos de 1990 y 2000", serie Población y Desarrollo, $\mathrm{N}^{\circ} 62$ (LC/L.2433-P), Santiago de Chile, Comisión Económica para América Latina y el Caribe (CEPAL). Publicación de las Naciones Unidas, $\mathrm{N}^{\circ}$ de venta: S.05.II.G.179.

Brain, Isabel, Gonzalo Cubillos y Francisco Sabatini (2007), "Integración social urbana en la nueva política habitacional", Temas de la Agenda Pública, año 2, N 7, Santiago de Chile, Pontificia Universidad Católica de Chile.

Castillo, María José y Rodrigo Hidalgo (2007), "1906/2006. Cien años de política de vivienda en Chile", serie Arquitectura, $\mathrm{N}^{\circ}$ 1, Santiago de Chile, Ediciones UnAB.

Domínguez Vial, Vicente y María de la Luz Nieto de los Ríos (1993), "Ahorro previo y subsidios para la adquisición de viviendas", Politicas de financiamiento habitacional en Chile, Santiago de Chile, Corporación de Investigación, Estudio y Desarrollo de la Seguridad Social (CIEDEsS).

Fundação João Pinheiro (2009), Déficit habitacional no Brasil em 2007, Belo Horizonte.

Garcia, Fernando y André Rebelo (2002), "Déficit habitacional e desigualdade da renda familiar no Brasil", Revista de Economia Aplicada, vol. 6, $\mathrm{N}^{\circ}$ 3, São Paulo.

Magnabosco, Ana Lelia (2011), "A política de subsídios habitacionais e sua influência na dinâmica de investimento imobiliário e no déficit de moradias do Brasil e do Chile", São Paulo, Pontifícia Universidad Católica de São Paulo.
MIDEPLAN (Ministerio de Planificación y Cooperación) (1996-2009), "Encuesta de Caracterización Socioeconómica Nacional", Santiago de Chile.

MINVU (Ministerio de Vivienda y Urbanismo) (2007), Un siglo de políticas de vivienda y barrio, Santiago de Chile.

Morandé, Eugenio (1993), "El mercado inmobiliario habitacional", Politicas de financiamiento habitacional en Chile, Santiago de Chile, Corporación de Investigación, Estudio y Desarrollo de la Seguridad Social (CIEDESS).

Muth, Richard (1960), "The demand for non-farming housing", The Demand for Durable Goods, Arnold C. Harberger, Chicago, The University of Chicago Press.

Simian, José Miguel (2010), "Logros y desafíos de la política habitacional en Chile", Estudios Públicos, $\mathrm{N}^{\circ}$ 117, Santiago de Chile, Centro de Estudios Públicos.

Stiglitz, Joseph y Andrew Weiss (1981), "Credit rationing in markets with imperfect information", American Economic Review, vol. 71, $\mathrm{N}^{\circ}$ 3, Nashville, Tennessee, American Economic Association.

Szalachman, Raquel (2000), "Perfil de déficit y políticas de vivienda de interés social: Situación de algunos países de la región en los noventa”, serie Financiamiento del Desarrollo, $\mathrm{N}^{\circ} 103$ (LC/L.1417-P), Santiago de Chile, Comisión Económica para América Latina y el Caribe (CEPAL), septiembre. Publicación de las Naciones Unidas, $\mathrm{N}^{\circ}$ S.00.II.G.89.

Tobin, James (1969), "A general equilibrium approach to monetary theory", Journal of Money, Credit and Banking, vol. 1, № 1, Ohio, Ohio State University Press. 